$\frac{2}{62}+82$

SANDIA REPORT SAND81-1848 - Unlimited Release • UC-66c

Printed April 1982

\title{
- An Assessment of Directional Drilling for Fossil-Energy Resources
}

Alan L. McFall

Prepared by

Sandia National Laboratories

Albuquerque, New Mexico 87185 and Livermore, California 94550

for the United States Department of Energy

under Contract DE-AC04-76DP00789

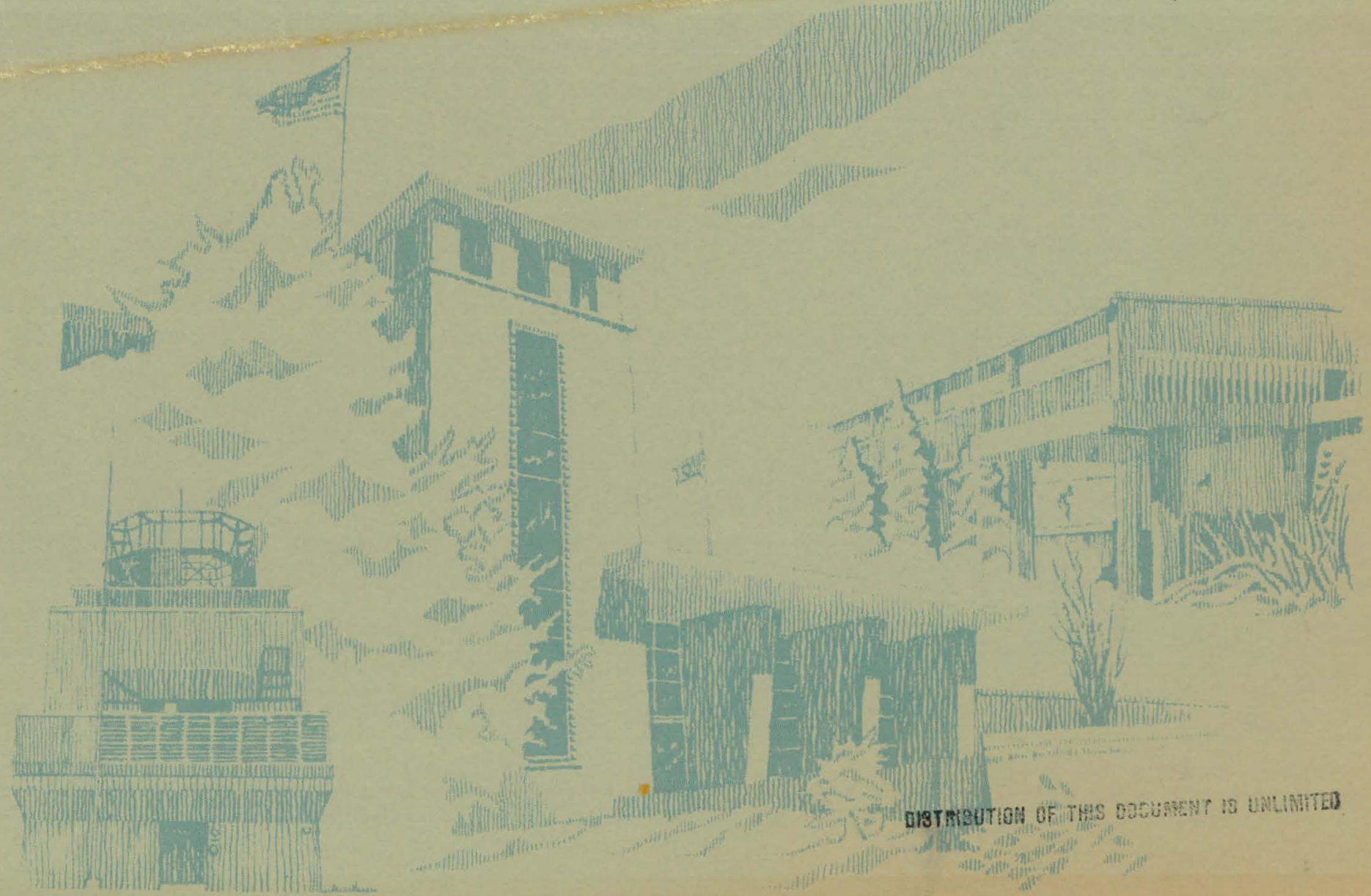




\section{DISCLAIMER}

This report was prepared as an account of work sponsored by an agency of the United States Government. Neither the United States Government nor any agency Thereof, nor any of their employees, makes any warranty, express or implied, or assumes any legal liability or responsibility for the accuracy, completeness, or usefulness of any information, apparatus, product, or process disclosed, or represents that its use would not infringe privately owned rights. Reference herein to any specific commercial product, process, or service by trade name, trademark, manufacturer, or otherwise does not necessarily constitute or imply its endorsement, recommendation, or favoring by the United States Government or any agency thereof. The views and opinions of authors expressed herein do not necessarily state or reflect those of the United States Government or any agency thereof. 


\section{DISCLAIMER}

Portions of this document may be illegible in electronic image products. Images are produced from the best available original document. 
Issued by Sandia National Laboratories, operated for the United States Department of Energy by Sandia Corporation.

NOTICE: This report was prepared as an account of work sponsored by an agency of the United States Government. Neither the United States Government nor any agency thereof, nor any of their employees, nor any of their contractors, subcontractors, or their employees, makes any warranty, expres or implied, or assumes any legal liability or responsibility for the accuracy, completeness, or usefulness of any information, apparatus, product, or process disclosed, or represents that its use would not infringe privately owned rights. Reference herein to any specific commercial product, process, or rights. Reference herin to any specific commercial product, process, or service by trade name, trademark, manufacturer, or otherwise, does not necessarily constitute or imply its endorsement, recommendation, or favoring by the United States Government, any agency thereof or any of their contractors or subcontractors. The views and opinions expressed herein do not necessarily state or reflect those of the United States Government, any agency thereof or any of their contractors or subcontractors.

Printed in the United States of America Available from

National Technieal Information Sorvioe

U.S. Department of Commerce

5285 Port Royal Road

Springfield, VA 22161

NTIS price codes

Printed copy: A05

Microfiche copy: A01 


$$
\text { SAND--81-1848 }
$$

DE82 017053

SAND $8 \overrightarrow{1-1} \overline{848}$

UNLIMITED RELEASE

Printed April 1982

\title{
AN ASSESSMENT OF DIRECTIONAL DRILLING FOR FOSSIL-ENERGY RESOURCES
}

\section{Alan I.. McFal1*}

Sandia National Laboratories Albuquerque, New Mexico 87185

\section{ABSTRACT}

This report discusses directional drilling techniques and procedures that can be used to access fossil energy resources. Unconventional resources such as tar sands, oil shale, and tight gas formations are specifically examined. Performance requirements, current practice, a description of drilling hardware, and a discussion of key developmental needs are presented.

\author{
prepared for \\ Morgantown Energy Technology Center \\ Morgantown, West Virginia 26505
}

* Presently employed by

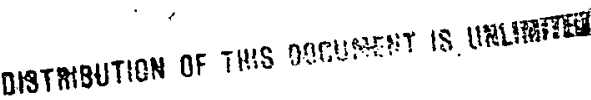
$\mathrm{NL}$ Industries 
ACKNOWLEDGMENT

Background information has been provided by the Department of Energy's Energy Technology Centers that are working on unconventional fossil energy recovery and by directional drilling service companies. Maturer Engineering, Inc., assisted in the preparation of this report.

ii 
DIRECTIONAL DRILLING REQUIREMENTS

High Angle Buildup Followed by Long Lateral Drilling

TECHNICAL NEEDS IN DIRECTIONAL DRILLING 37

CONCLUSIONS AND RECOMMENDATIONS ? 45

REFERENCES 48

$\begin{array}{ll}\text { APPENDIX } & 50\end{array}$

State-of-the-Art of Directional Drilling Elements 50

Drill Bit Thrusters $\quad 54$

Steering Tools 59

Downhole Drilling Motors 68

Downhole Survey Instruments $\quad 72$

Drilling Rigs 


\section{INTRODUCTION}

Recovery of many fossil fuel resources requires the capability to drill holes that are deviated from vertical. Such procedures are called directional drilling and they have been developed to allow the accessing of target locations that are displaced horizontally and vertically from the start of the wellbore. The evolution of modern directional drilling practices has been prompted by offshore petroleum developments where multiple wells have been completed from a single drilling platform. Special hardware and techniques have been developed to achieve wellbore path control and to insure that the desired target is intersected.

Mechanical fixtures known as whipstocks and the fluid pressure from jets have been used to direct the bit; however, a recent practice has been to utilize a downhole fluid motor with a bent sub or housing to control the change in the angle of the deviated borehole. Specific placement of the borehole path is accomplished with the use of frequent surveys, with each survey followed by application of the proper directional corrective measure. The interrelationship between drilling, controlling, and surveying is depicted in Figure 1.

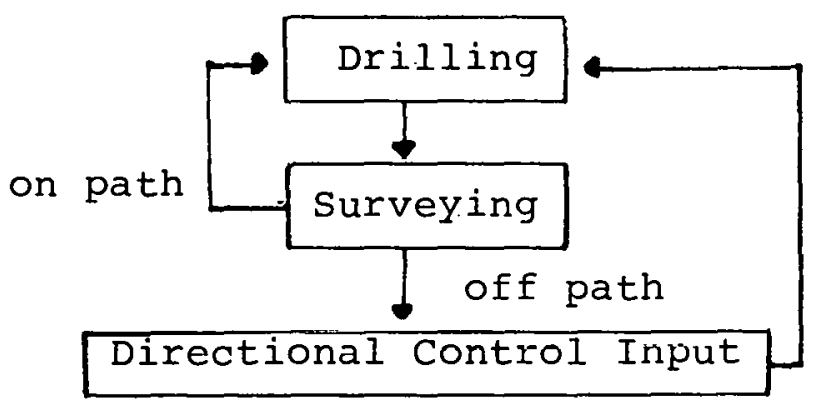

Figure 1. Directional Drilling Practice 
High costs, reduced rates of penetration, and other drilling problems currently limit the use of directional drilling to those applications where economic adyantages are clearly realizable (e.g., offshore) or where drilling might otherwise be difficult or prohibited (e.g., accessibility or regulatory concerns). Consequentily, programs to achieve improved efficiency and expanded scope in directional drilling practices are required.

In recent years, several applications for directional drilling have emerged that will make the recovery of additional fossil fuel resources possible. These include horizontal and slant hole drilling into coal seams for draining and recovering methane and to access heavy oil and tar sands deposits, vertical to horizontal drilling for in-situ coal gasification, oil shale retorting, and mineral leaching. Also appearing are extended reach drilling (ERD) for offshore oil and gas: and small radius drainhole drilling to improve oil drainage and reduce gas coning. These and other directional drilling applications will require the extension of drilling technology: and hardware.

Significant adyances in controlling the path of the wellbore have been made. 1 However, the interdependence of drilling, monitoring, and controlling (Figure 1) will become more critical as directional holes:

$\because$ approach horizontal

- are shallow with high angle buildup

- are longer

- are directed towards smaller targets

A portion of current research work is directed at reducing the 
sensitivity (cost) of these separate elements by developing advanced systems which integrate directional drilling functions. These are typified by real-time steering and measurement-while-drilling systems.

The purpose of this study is to summarize current directional drilling practices and equipment and review recent experiences in drilling non-typical directional wells as related to coal, tar sands, etc. This background information will identify research and development projects which impact fossil energy recovery.

The report is based on key sections which give:

- Reasonable directional drilling performance requirements based on resource characterization and production techniques

- Current directional drilling practice

- Non-typical directional drilling experience

- Technical advances needed to upgrade directional drilling technology to satisfy the performance requirements

- An appendix of state-of-the-art in directional drilling equipment and procedures. 


\section{DIRECTIONAL DRILLING REQUIREMENTS}

The objective of directional drilling is to drill along. a predetermined path to a target using drilling practices that are economically feasible. Successful directional drilling programs are being conducted daily throughout the petroleum industry; however, current oil and gas directional drilling practices do not directly transfer to the exploitation of unconventional energy sources such as:

1. enhanced gas and oil recovery

2. methane drainage from coal

3. in-situ coal gasification

4. in-situ oil shale recovery

The main differences between conventional petroleum directional drilling requirements and those for the above applications are the desired hole configuration, and the location and properties of the formation. Specific performance requirements vary with each resource and production system. The following are requirements which apply, in general, to the development of unconventional energy sources.

Hole Configuration: Wellbore configurations may be vertical, horizontal, slanted with high curvature, or a combination of the three. For example, holes for draining methane from coal have been drilled horizontally, starting at the coal face, into an underground seam for distances of 1000-3000 ft. A1so, high curvature wellbores have'been drilled with a full $90^{\circ}$ 
angle change from vertical at ground level to horizontal at the coal seam; wellbore radius of curvature depends on the depth of the seam. The selected wellbore configuration is also related to production technique, cost, sweep efficiency, etc.

Hole Size: Hole diameter is often less than 6 inches in order to minimize drill rig requirements. This means that all downhole equipment, such as motors, bits, drill pipe, collars, and stabilizers must be scaled down. Two-inch drill pipe is commonly used in drilling these shallow, slim directional wells. This size pipe is very flexible and places an additional burden on directional control.

Hole Location: The actual wellbore is constrained to follow the planned path with a specified margin of error. Location can be critical, on the order of one foot or less, for very thin coal seams. This places greater accuracy requirements on surveying methods and directional control. In addition, the orientation of the wellbore would be critical if slant hole drilling is followed by horizontal drilling. In-situ processes that are based on horizontal drilling to achieve communication between vertical wellbores will require methods to accurately locate the borehole in the horizontal plane. Formation Problems: Formations within 2000 feet of the surface are often fragmented and the fracture gradient is low. This affects directional control of the borehole and the accompanying problem of lost circulation can reduce chip 
removal efficiency. Many formations encountered in heavy oil and tar sands reservoirs are unconsolidated, and drilling horizontal holes presents serious borehole stability problems. Coal, although relatively easy to drill, has many features which may deflect the bit from the desired path. Properties such as washouts, partings, folds, pyrite balls, clay inclusions, etc., can cause this deviation.

Specific directional drilling performance requirements for the development of both conventional oil and gas and unconventional fossil resources are discussed below without regard to present technical limitations or the status of past or current developments. They are intended to reflect current thinking on the optimum manner to access and produce the specific resource type. Possible directional drilling. techniques and hardware to achieve these requirements will be evaluated in following sections.

\section{Conventional Oil and Gas}

Deviated holes are required for a large number of varied applications in this resource type. In response, directional drilling: technology has been derived and guided within the scope of this need.

Completion of multiple wells from a single pad or platform is an integral part of economic drilling. This is especially true for offshore drilling and the Alaskan north slope. Reaching the maximum resource from one drilling 
location maximizes the economic benefit. As a result, the conventional horizontal distances that can be achieved from conventional drilling locations have increased over the years. There is a current need to drill distances up to 25,000 feet 1aterally. This is about double present capabilities. These long holes will require improved methods for the efficient removal of the cuttings from the hole. Also, thrusters may be required to advance and remove the drill string. Improved sensors capable of measuring bit position to within a five foot sphcre of accuracy at 10,000 feet measured depth are desirable. This represents an order of magnitude improvement over what is typically used presently for conventional oil and gas recovery. A better understanding of the bottomhole assembly dynamics (BHAD) in these long, near horizontal, holes is necessary to insure bottomhole stability for both present and new drilling tools.

There are times when specialized directional drilling requirements are necessary to sidetrack pipe stuck in the hole or to kill a well that has blown out. These instances require the utmost in survey accuracy and control of the bottomhole assembly. Devices (accoustic, magnetic, etc.) to sense the precise location of a nearby wellbore are required.

\section{Unconventional Oil Recovery}

The performance requirements for the emerging technologies associated with unconventional oil recovery are undergoing 
constant change. As new techniques for accessing and producing the resource are conceptualized and developed, the needed directional drilling requirements become evident.

The directional drilling requirements for heavy oil (API gravity $<16-20^{\circ}$ ) reservoirs are often directed by the production configuration of the wellbore system. Such techniques as steam drive, gravity drainage, and multiple infill holes are frequently used. A desirable goal for improved recovery is the ability to drill high angle and horizontal holes. The development of thrusters, improved sensing and guidance, and a procedure for removing the chips from the hole will be required. The highly deviated drilling. in these formations will also require methods to insure borehole integrity. The completion of multiple horizontal holes from a single vertical wellbore could be beneficial for steam injection or gravity drainage. Large numbers of infill holes will be required. As these are shallow holes, efficient portable rigs will be required.

Current directional drilling requirements for tar sands parallel many of those described for heavy oil. Additional needs arise due to the hard shallow infill drilling, because adequate loads cannot be applied to the bit, and large rocks in the drill path tend to deflect the bit. It is desirable to drill large (12-1/4.") infill holes using small, truck mounted rigs. As a result, developments are required in the BHAD of large bits on small drill rod to control deviation 
problems. If the resource is to be mined, directional drilling in advance of the mining may be roquired.

Significant advancements in the state-of-the-art of directional drilling will be required in order to recover oil from tight shale formations where radial drilling for explosive fracturing and chamber creation is required. In-situ retorting processes will take on various configurations with horizontal linking a strong possibility. A series of wellbores, very accurately aligned, will require improved hole surveying techniques.

Unconventional Gas Recovery

Unconventional gas recovery may include tight gas formations such as sands and shales, the recovery of methane from coalbeds, and the conversion of coal by gasification. Tight gas formations will require radial drilling for explosive fractures or directed hydrofrac. Methane drainage from coal requires long horizontal holes. Fracturing is not always possible in seams that are to be mined at a later date. This drilling can take place at the seam face in an existing mine, but must be conducted from the surface in deep unmineable seams or when drainage in advance of mining is desirable for safety. Horizontal holes from 1000-3000 feet are desirable. Multiple holes to increase drainage effectiveness are required. Sensing and telemetry developments to keep the hole path within the seam, and thrusters and steering devices will be needed. 
Some gasification techniques require horizontal holes and in many cases, linking to another vertical well is a major objective. This will require the development of accurate sensors and steering tools.

A summary of the requirements for fossil energy directional. drilling is presented in Table I. These requirements for developing new directional drilling techniques and equipment must be carefully evaluated against more conventional methods with regards to performance, schedule, risk, and cost.

\section{CURRENT DIRECTIONAL DRILLING PRACTICE}

The configuration of a directional well usually depends on geological structures and the location of the producing zones with respect to lease lines and spacings. According to present practice, there is one hole bottom per wellbore; branch or lateral drainhole type drilling is not common practice.

An important factor in the success of a directional well is the selection of the "kick off point" or the depth at which the directionally drilled section is to be started. Higher drift angles, in the $15^{\circ}$ to $45^{\circ}$ range, allow greater flexibility in selecting the most desirable kick off point and give greater stability of direction than smaller angles in the $5^{\circ}$ to $10^{\circ}$ range. Drill bits have a natural tendency to move laterally as they penetrate along the vertical axis ("walk") so the directional plan must allow for this displacement. 


\begin{tabular}{|c|c|c|c|c|c|c|c|}
\hline \multirow[b]{2}{*}{$\begin{array}{l}\text { DIRECTIONAL DRILLING } \\
\text { PERFORMANCE REQUIREMENTS }\end{array}$} & \multirow[b]{2}{*}{$\begin{array}{l}\text { CONVENTIONAL } \\
\text { OIL \& GAS }\end{array}$} & \multicolumn{3}{|c|}{ UNCONVENTIONAL OIL RECOVERY } & \multicolumn{3}{|c|}{ UNCONVENTIONAL GAS RECOVERY } \\
\hline & & $\begin{array}{l}\text { HEAVY } \\
\text { OIL }\end{array}$ & $\begin{array}{l}\text { TAR } \\
\text { SANDS }\end{array}$ & $\begin{array}{l}\text { OIL } \\
\text { SHALE }\end{array}$ & $\begin{array}{l}\text { TIGHT } \\
\text { GAS }\end{array}$ & $\begin{array}{l}\text { METHANE } \\
\text { FROM COAL }\end{array}$ & $\begin{array}{c}\text { COAL } \\
\text { CONVERSION }\end{array}$ \\
\hline \multicolumn{8}{|l|}{ HOLE CONFIGURATION REQUIREMENTS } \\
\hline HIGH ANGLE - LONG LATERAL & $\mathbf{x}$ & & & & $\mathbf{x}$ & & \\
\hline HIGH ANGLE - SHALLOW TARGET & & & $\mathbf{x}$ & & & $x$ & $\mathbf{x}$ \\
\hline LATERAL DRAIN HOLES & & $\mathbf{x}$ & $x$ & $\mathbf{x}$ & & $x$ & $\mathbf{x}$ \\
\hline HORIZONTAL HOLES & & $\mathbf{x}$ & $\mathbf{x}$ & & & $\mathbf{x}$ & $\mathbf{x}$ \\
\hline PERCISION VERTICAL HOLES & & & & $\mathbf{x}$ & $\mathbf{x}$ & & \\
\hline LARGE DIA. SHALLOW HOLES & & $x$ & $x$ & $x$ & & & \\
\hline \multicolumn{8}{|l|}{ INSTRUMENTATION REQUIREMENTS } \\
\hline HIGH ACCURACY SURVEY TOOLS & $\mathbf{x}$ & & & $\mathbf{x}$ & & $\mathbf{x}$ & $x$ \\
\hline RELIABLE TELEMETRY SYSTEMS & $x$ & $\mathbf{x}$ & $x$ & $\mathbf{x}$ & $x$ & $\mathbf{x}$ & $x$ \\
\hline COAL SEAM INTERFACE SENSOR & & & & & & $x$ & $x$ \\
\hline $\begin{array}{l}\text { MEASUREMENT WHILE DRILLING } \\
\text { SYSTEMS }\end{array}$ & $x$ & & & & $\mathbf{x}$ & . & \\
\hline \multicolumn{8}{|l|}{ DRILLING REQUIREMENTS } \\
\hline $\begin{array}{c}\text { MULTIPLE HOLE RE-ENTRY } \\
\text { CAPABILITY } \\
\end{array}$ & & $x$ & $x$ & & $x$ & $\mathbf{x}$ & \\
\hline THRUSTER SYSTEMS & $\mathbf{x}$ & $x$ & $\mathbf{x}$ & & & $x$ & $x$ \\
\hline BOREHOLE STABILITY TECHNOLOGY & & $x$ & $x$ & $\mathrm{x}$ & & $x$ & $x$ \\
\hline CUTTINGS REMOVAL TECHNOLOGY & $x$ & $x$ & $x$ & & & $x$ & $x$ \\
\hline FLUIDS & $x$ & $x$ & $\mathbf{x}$ & $\mathbf{x}$ & & & \\
\hline $\begin{array}{c}\text { ANALYSIS AND CONTROL OF } \\
\text { DRILLING SYSTEMS }\end{array}$ & $x$ & $x$ & $x$ & & $\mathbf{x}$ & & \\
\hline
\end{tabular}

TABLE I

DIRECTIONAL DRILLING PERFORMANCE REQUIREMENTS 
Otherwise, resisting the bits'normal tendencies would only result in increased rig time. Mathematical graphs, called "build up charts", may be used in planning the drilling program. An example drilling plan is presented in the following table:

\begin{tabular}{|c|c|c|}
\hline \multirow[t]{5}{*}{ Given: } & K.o.P. (Kick Off Point) & $2,000 \mathrm{ft}$ \\
\hline & T.V.D. (True Vertical Depth) & $10,000 \mathrm{ft}$ \\
\hline & Deviation (Horizontal Deviation) & 2,455 \\
\hline & Build Up & $2^{\circ}$ per 100 \\
\hline & Direction & N. $30^{\circ} 45^{\prime} \mathrm{E}$ \\
\hline
\end{tabular}

The build up charts give maximum angle of deviation, measured depth, true vertical depth, and horizontal deviation corresponding to the maximum angle (2).

The type of formation at the selected kick off point is a prime factor in choosing a suitable deflection tool. Normally, formation hardness is the controlling criteria. Types of deflection tools are: whipstocks, jet bits, and bent subs or housings. The applicability of each tool as a function of formation hardness is summarized in Figure 2 (1). Whipstocks are used with a drilling assembly consisting of a properiy sized whipstock drill bit, a spiral stabilizer, and an orienting sub rigidly attached to the whipstock by a shear pin. Once the assembly is lowered to the bottom of the hole and oriented, proper weight is applied to set the whipstock and shear the pin. The bit then drills about 12 to $16 \mathrm{ft}$ below the toe of the whipstock. A pilot bit is then used to 
Approximate

Penetration Rates (Ft/Hr)

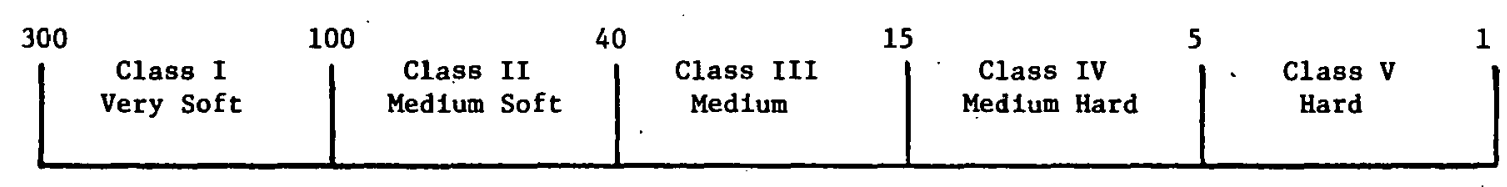

Whipstock
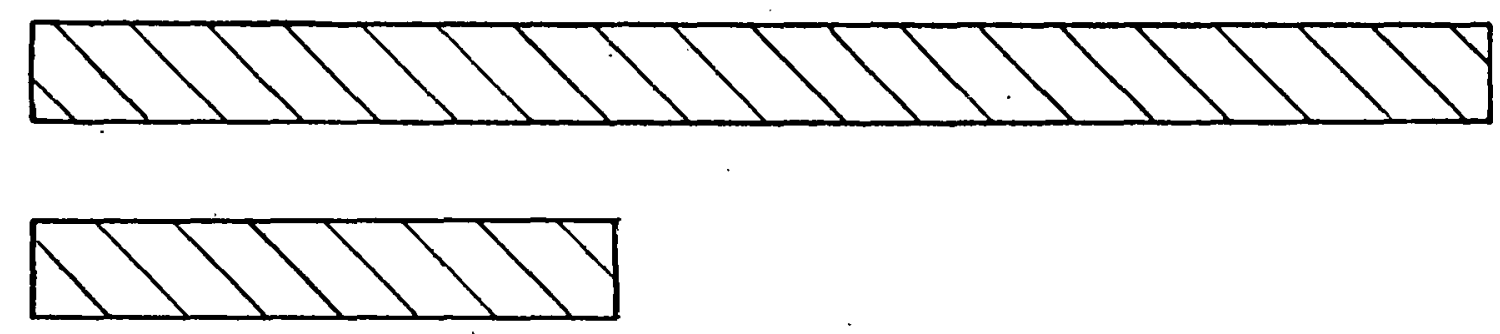

Motor with Bent Sub

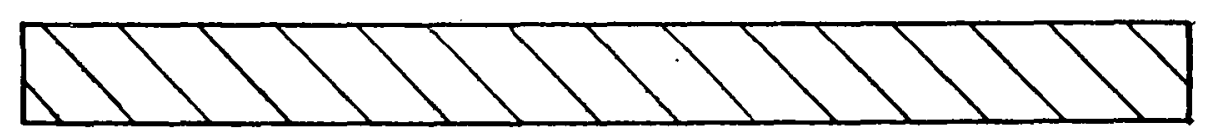

F1gure 2. Tool Applicability as a Function of Formation Hardness 
open the hole to the required diameter, and a survey is made to record the amount of deflection. Typically four trips are required to establish a deviated hole by whipstock methods.

The jet bit is a fast and economical deflection tool which is used to deviate wellbores in soft formations. It is a modified roller cone bit with one large nozzle. This nozzle is oriented in the desired course direction and used to wash a cavity. Short drilling periods, when alternated with jetting, produce the deviated hole.

The downhole motor with a bent sub is currently the most widely used deflection tool. A bent sub builds hole angle in a given plane which is established by the proper orientation of the bottomhole assembly. Mud motors are used because the drill pipe must not rotate when a bent sub (or housing) is in the drill string. Holding the desired hole orientation is difficult to achieve while drilling because the motor reaction torque causes reverse drill pipe twisting.

Downhole motors and bent subs can be used to drill a full gauge hole at the kick off point, thus eliminating costly follow-up trips to ream the hole to full gauge. Trajectory adjustments are also more accurate since the motor penetrates along a smooth, gradual curve. Downhole motors eliminate the need for clean up trips due to bridges, dog legs, etc. Once the initial deflection and direction of the well are established, directional control is, for the most part, accomplished with conventional rotary drilling techniques. For 
example, packed hole assemblies are used to maintain inclined hole direction.

Wellbore orientation and bottomhole location are not measured directly but are calculated from periodic drift and azimuth angle measurements. Incremental changes are predicted between two measurement locations according to various calculation methods (3). API recommends the Average Angle Mcthod because it provides a reasonable degree of accuracy without the use of sophisticated computational equipment.

Most wellbore surveys are made with single shot magnetic or gyroscopic instruments. These instruments are lowered through drill pipe on a wireline while the survey is being made. Photographs of azimuth and drift readings are taken by the downhole instrument package and these photographs become a permanent record of the wellbore. A multi-shot survey instrument can be used to record direction measurements at several different wellbore stations.

Recently developed instrumentation systems allow downhole directional information to be transmitted to the rig while drilling. Electric cables transmit downhole directional parameters which are interpreted and displayed for the directional driller. This system is used only when bent subs and downhole motors are used to build hole angle. Advanced telemetry systems, such as mud pulse, will allow continuous transfer of downhole directional data while drilling. A more complete description of the hardware finding 
application in directional drilling is presented in the appendix. Included are descriptions of drill bits and bit thrusters, steering tools, drilling motors, drilling rigs, and surveying instrumentation.

\section{NON-TYPICAL DIRECTIONAL DRILLING EXPERIENCE AND EQUIPMENT}

This section reviews field experience in drilling different types of non-typical directional wellbores. A description of unique hardware developed for some of these non-typical applications is also presented.

\section{High Angle Buildup Followed by Long Lateral Drilling}

Typical oil and gas hole configurations have target coordinates around $10,000 \mathrm{ft}$ vertical distance and 12,000 ft. lateral distance. The high cost of offshore installations, such as platforms, subsea wellheads, and flow lines, is giving impetus to drilling that results in a much greater lateral to. vertical distance ratio.

In 1975, Tenneco 0il Company drilled three high angle holes $\left(60^{\circ}, 70^{\circ}\right.$, and $\left.80^{\circ}\right)$ from a single platform (4). By increasing the angle from $60^{\circ}$ to $80^{\circ}$, the reservoir area that the well can investigate increased over sevenfold. Figure 3a shows how the hole angle was built at $4^{\circ}$ per $100 \mathrm{ft}$ to $80^{\circ}$ and then a high angle straight hole drilled to the target. The casing program is shown in Figure $3 \mathrm{~b}$. 


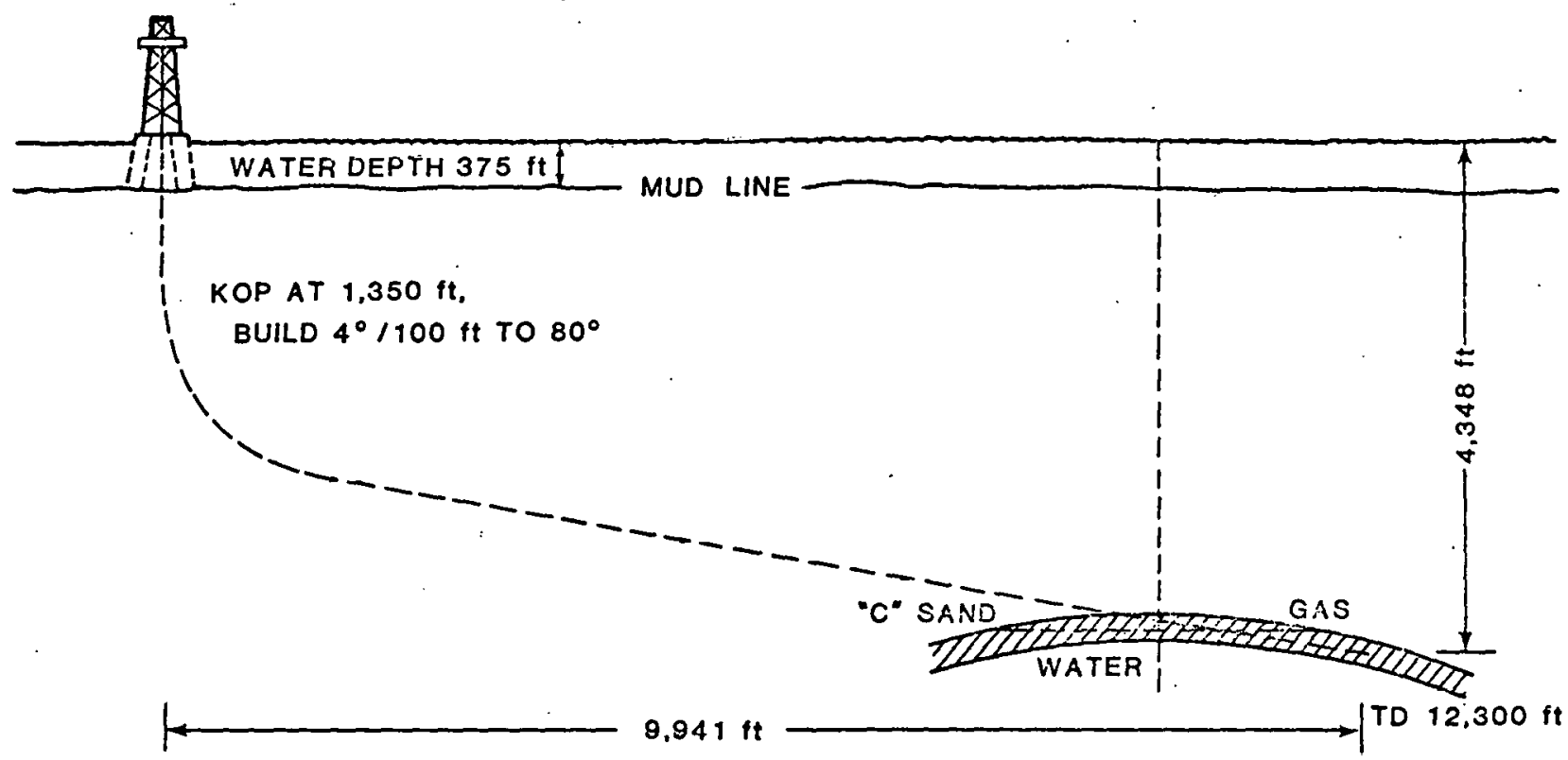

a. We1l Profile

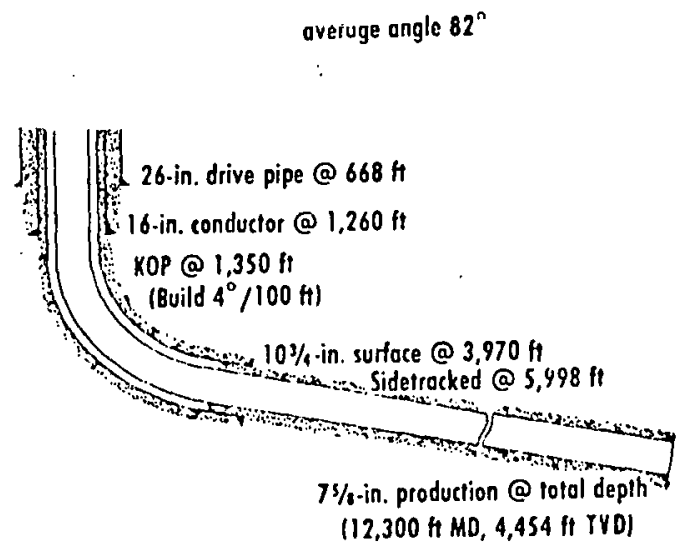

b. Casing Schematic

Figure 3. Tenneco High Angle Hole 
Planning was a key factor in the success of these wells. Drilling rig selection and modifications were made to maximize drilling efficiency in order to prevent any downtime during drilling that might result in loss of the hole. An extensive review of high angle drilling in the area of this offshore installation, along with an action plan, helped to provide a technically and economically sound basis for this high angle drilling program.

Angle buildup using a downhole motor and bent sub began after a 16 inch conductor pipe was cemented. The directional hole was kicked off at 1,350 ft with a Dyna-Dril1 and a 9-7/8 inch bit, building about $4 \% / 100 \mathrm{ft}$. This bit size was selected instead of a 15 inch bit to maintain closer directional control. The 9-7/8 inch surface hole was opened to 15 inches with a bullnosed hole opener. A $10-3 / 4$ inch surface casing was set after the angle: buildup was completed allowing a relatively. straight shot to total depth.

There is little technology or experience for designing bottomhole assemblies to hold the constant angle required for the high angle hole shown in Figure 3. Great care was exercised to insure borehole stability. Single shot surveys were taken about every 180 to $240 \mathrm{ft}$ and after each survey, the drilling parameters were altered to keep the angle in check.

\section{High Angle Buildup Followed by Drop in Angle}

Directional wells reaching maximum angles of $74^{\circ}$ have 
been drilled by THUMS (5). They report a few problems with sticking pipe and hole stability. Success is again attributed to the establishment of a sound technical drilling plan. A typical well profile is given in Figure 4 .

In this case it was determined that angle buildup must be limited to $6^{\circ}$ per $100 \mathrm{ft}$ and maximum hole angle held to $70^{\circ}$. Drop-off rate is limited by the ability or inability of the bottomhole assemblies to deflect the hole downward.

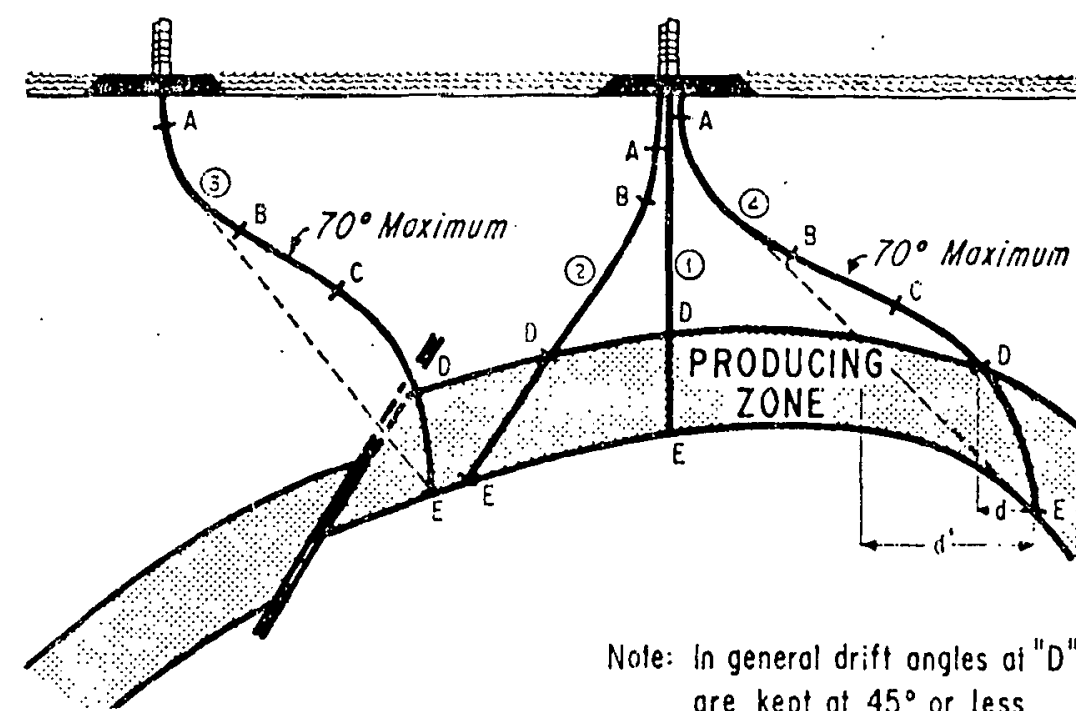

ore kept of $45^{\circ}$ or less

Figure 4. THUMS Well Profile

Experience indicates that even at slow drilling rates, angle reduction greater than $2-1 / 2^{\circ}$ per $100 \mathrm{ft}$ can rarely be attained.

High Angle Buildup to a Shallow Formation

High angle holes are also being drilled into fossil fuel 
bearing formations lying within a few hundred feet of ground level. Total angle for these holes is near $90^{\circ}$. The objective here is to penetrate the formation with a horizontal hole section after total angle is achieved. Horizontal holes allow better resource recovery rates than do vertical holes penetrating through the same formation. Four wellbores of this type are discussed below.

1. Esso Resources Ltd. of Canada has successfully drilled and completed a $90^{\circ}$ total angle wellbore and penetrated a $260 \mathrm{ft}$ tar sand zone 1,452 ft deep (6): Details of this wellbore are shown in Figure 5. It is the first well of this type and will be used in an in-situ recovery pilot operation at Cold Lake, Canada. Other wells in this area have been deviated up to $35^{\circ}$ from the vertical.

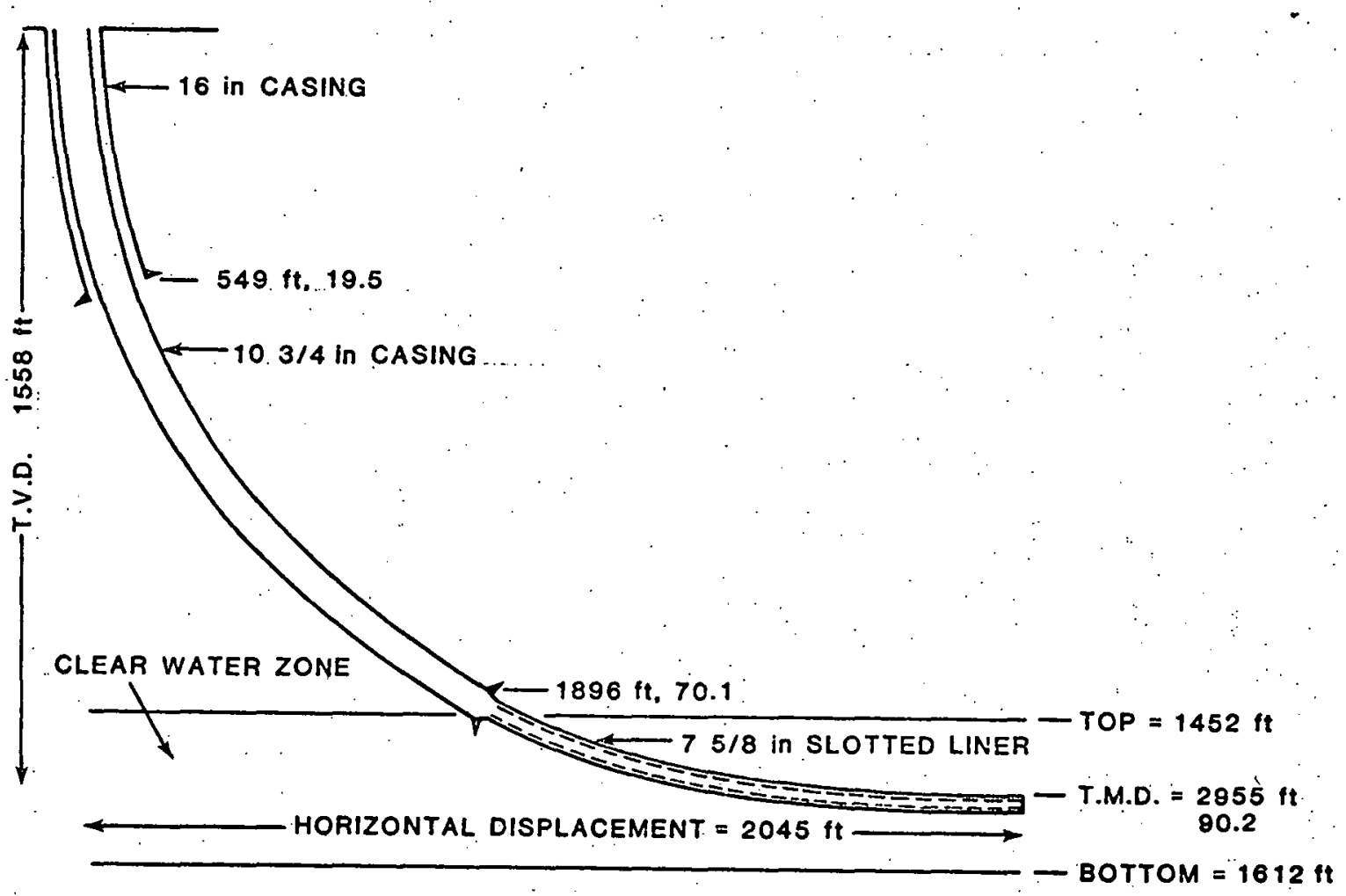

Figure 5. Esso Resources Tar Sands We11 
An angle building assembly and a hole opening assembly were the two types of downhole assemblies used to drill this we11. The angle building assembly consisted of a mill tooth bit rotated by a Dyna-Drill motor. A 6-1/2 inch Dyna-Drill was used in both the 12-1/4. inch and the 9-1/2 inch pilot holes. Angle building was accomplished using either a bent sub or a bent housing Dyna-Drill. The three bent subs used were $1.5^{\circ}, 2^{\circ}$, and $2.5^{\circ}$. Heavy weight drill pipe was run immediately behind monel collars so that steel drill collars could be placed further uphole in the more vertical section of the hole, providing weight on bit. This is contrary to current directional drilling practice, but no pipe buckling problems were noted. This drill string assembly also reduced the chances of differential sticking. The hole opening assembly consisted of a pointed bullnose, a non-rotating stabilizer, and a reamer.

Directional surveys played a critical role in the success of the project. The horizontal portion of the hole was to be located near the bottom of the tar sand formation. A real-time survey tool was used at all times in the pilot holes. Single shot magnetic surveys were also run every $60 \mathrm{ft}$ to provide a permanent survey record as the hole progressed. A telephone link from the drilling location to an IBM 370 computer in Edmonton was available and continuous computation of the hole trajectory was performed.

As the hole inclination approached higher angles, the 
frictional drag on the drill string increased and satisfactory weight on bit became more difficult to maintain. Drill string drag during trips was usually about 10,000 to 15,000 pounds. The most troublesome problem occurred in enlarging the 12-1/4 inch pilot surface hole. Initial efforts to ream the pilot hole with a $30 \mathrm{ft}$ long bullnose were unsuccessful. A short non-rotating stabilizer positioned ahead of the hole opener was able to follow the pilot hole successfully. An angle buildup rate of $4-1 / 4^{\circ}$ per $100 \mathrm{ft}$ was maintained with 12-1/4 inch bits. All casing strings went in very smoothly. 2. In 1975, Morgantown Energy Research Center (MERC) contracted to have a high angle hole drilled into a coal seam near Pricetown as part of a program to study underground coal gasification (7). The coal bed is $880 \mathrm{ft}$ below ground level and is $6 \mathrm{ft}$ thick at the test site (see Figure 6).. The objective of the drilling program: was to build hole angle.until reaching the coal seam and then drill horizontally in the coal bed for a distance of $500 \mathrm{ft}$. It was necessary to tilt the derrick an angle of $10^{\circ}$ and build hole angle at a rate of $5-1 / 2^{\circ}$ per $100 \mathrm{ft}$. Approximately $60 \mathrm{ft}$ of surface casing was set, and then a 3 inch pilot hole drilled until the coal seam was penetrated. The hole was then reamed out to $7-7 / 8$ inch and 5,-1/2 inch casing was set from the coal seam to the surface. Drilling continued horizontaliy with a $4-3 / 4$ inch bit for approximately $500 \mathrm{ft}$. Drilling was accomplished with $2-3 / 8$ inch Dyna-Drill downhole motors. Problems encountered during the 
10-1/2 month drilling program fall into the following categories:

(1) Rig Trip Time

(2) Mechanical Failures

(3) Plugging and Sidetracking

(4) Hole Surveying and Tool Orientation

(5) Reaming

(6) Lost Circulation

(7) Pump Repairs

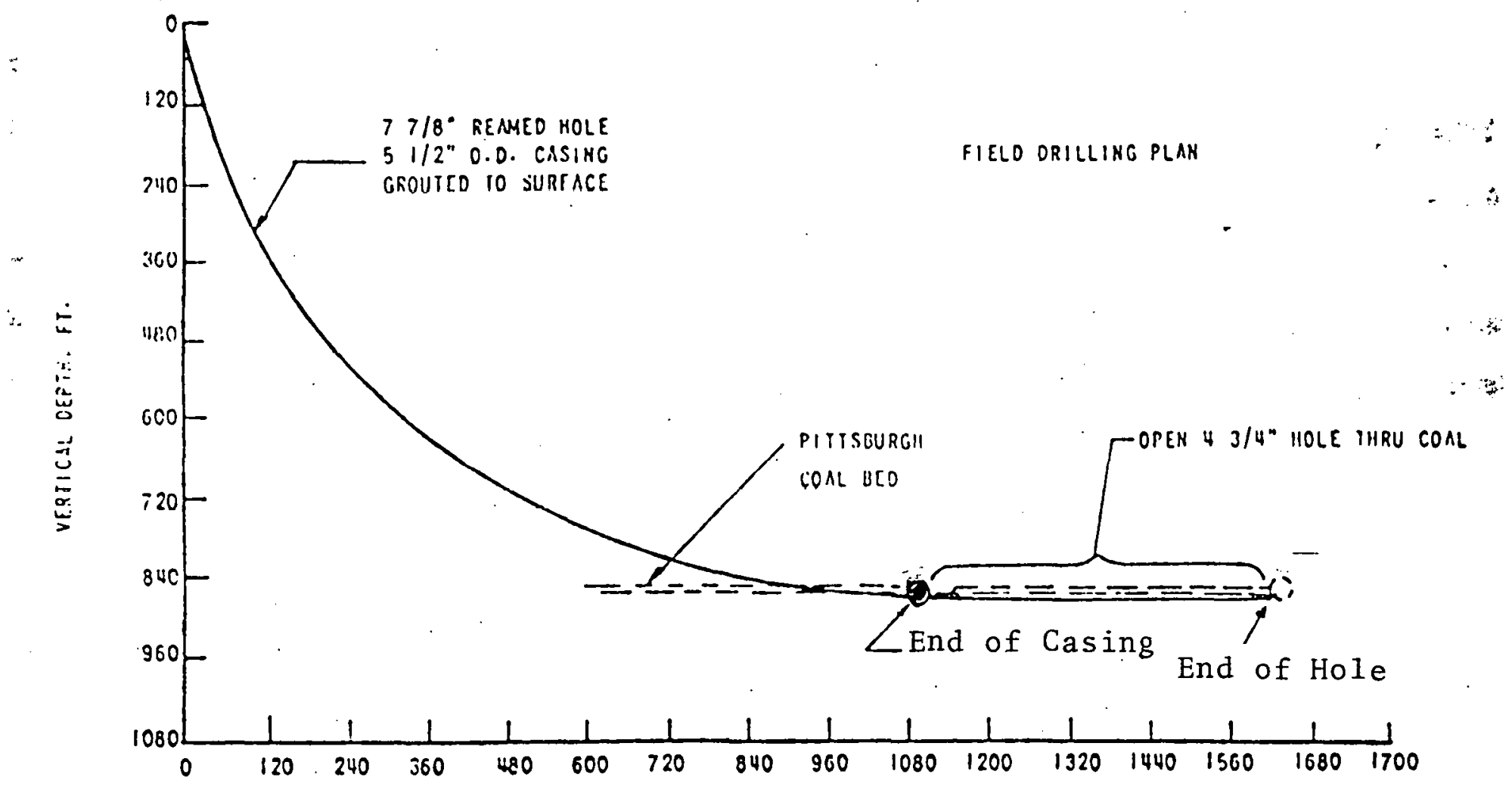

Horizontal Distance

Figure 6. Pricetown Slant Hole 
This drilling program. showed that high angled directional wells can be drilled and inserted into narrow coal seams for at least $500 \mathrm{ft}$. However, this was an experimental drilling program and the costs were high. The cost of drilling this type of hole must be greatly reduced for in-situ coal gasification to be commercially feasible.

3. Slant hole drilling from the surface using directional drilling techniques is being evaluated by the U. S. Bureau of Mines (USBM) as an alternate method for drilling horizontally into coal seams. Drilling is conducted from the ground surface instead of at the coal face and requires accurate directional surveying and bit control to hit the coal seam at a near horizontal slope (see Figure 7). Their project includes drilling into the Pittsburgh coal bed at the Emerald Mine near Waynesburg, PA (8).

One goal of the USBM project was to drill a circular arc directional well having a planar radius of about $1,000 \mathrm{ft}$ and then continue the drilling program horizontally into a coal seam. This wellbore was drilled with a truck mounted drilling rig using a 2-3/8 inch Dyna-Drill having a bent housing.

Bit force was generated by hydraulic cylinders pushing down on the drill pipe at the surface. Part of this push down load was absorbed by friction and confining forces along the drill pipe so the magnitude of the bit force was not exactly known during the drilling. The axial bit force component, however, was monitored reasonably well from the known pump pressure. The Dyna-Drill is a positive displacement 
motor so pressure drop across the motor is a good indicator of output torque and thus bit thrust force.

Accuratc directional surveying using Eastman Whipstock magnetic singleshot equipment was a key factor in the successful drilling of this hole.

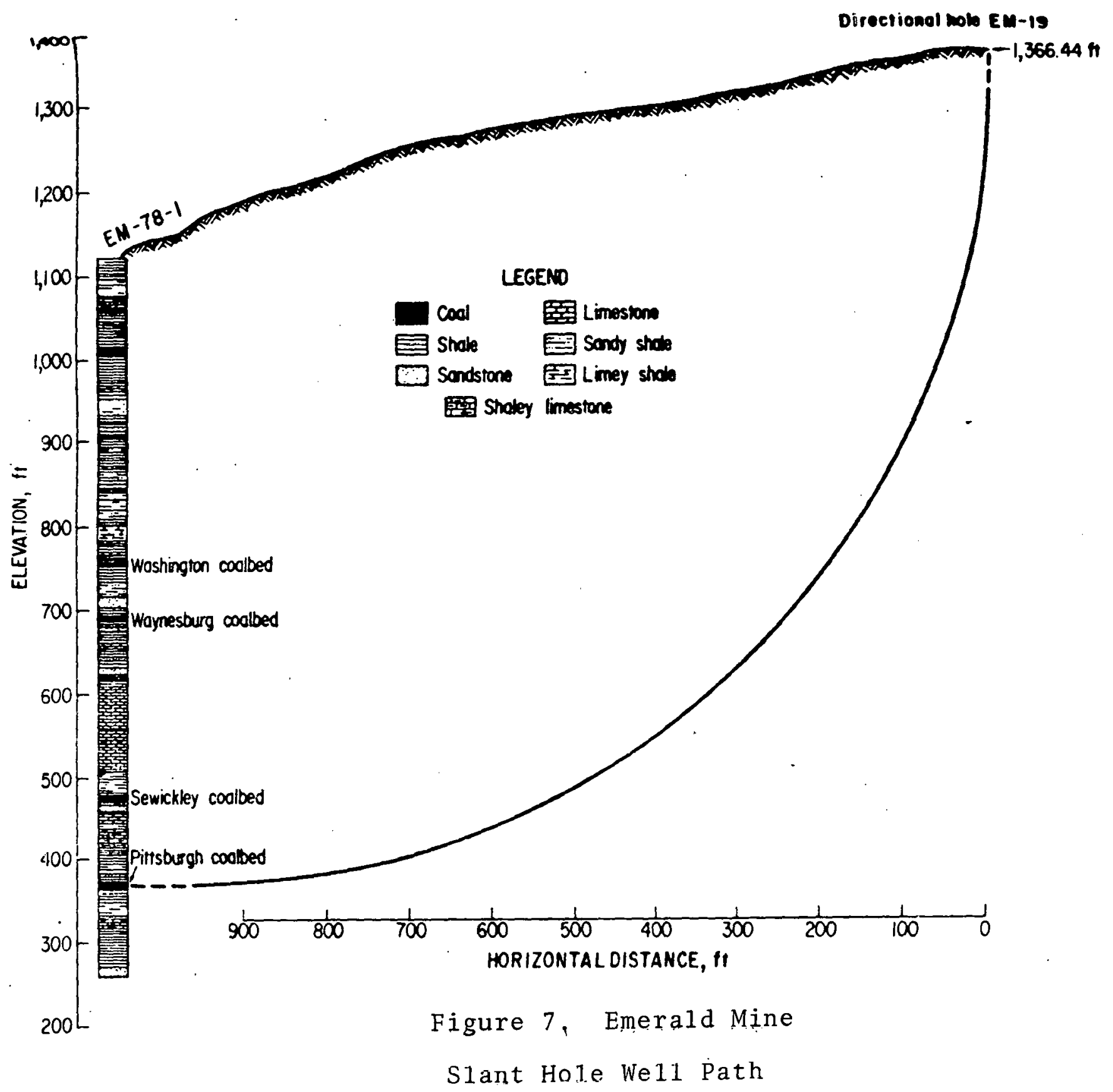


4. Lawrence Livermore Laboratory recently drilled a directional hole to penetrate a coal seam at Hoe Creek, Wyoming. The driling rig was slanted about $30^{\circ}$ and hole angle was developed at a rate of $5^{\circ}$ per $100 \mathrm{ft}$ in order to horizontally penetrate a coal seam about $150 \mathrm{ft}$ below the surface. The coal seam was $25 \mathrm{ft}$ thick. The horizontal portion of the hole in the coal seam was approximately $200 \mathrm{ft}$ long.

Low penetration rates of 3 to $5 \mathrm{ft} / \mathrm{hr}$ were experienced due to low. bit force and the need to use diamond bits. Diamond bits were used because conventional roller bits cannot be used much above 150 RPM; the Dyna-Drill operated at 400 RPM. Low bit force was required to maintain directional control.

Extremely High Curvature Holes (Drainholes)

Holes that are drilled horizontally from vertical wellbores are called drainholes: More than one drainhole may be drilled and holes have been drilled with radii of curvature as small as $11-1 / 2 \mathrm{ft}$. Tools marketed by Holbert (9) drill with a radius of curvature of $38.2 \mathrm{ft}$ and build angle at the rate of $1-1 / 2^{\circ}$ per foot. Holbert's downhole equipment is shown in Figure 8 . The flexible drill pipe is a key element. It is made from. standard drill collars by torch cutting multiple four lobed universal joints. "Drilling mud is pumped through a hose attached to fittings inside the box and pin connections. 
A special universal joint directly above the bit is designed to concentrate the force applied to the bit at a point below the center line of the hole. Consequently the bit, acting as a lever with the blades of the reamer as a fulcrum, is forced to dig to the high side of the hole. This causes a continual increase in angle as hole is drilled.

Tools based on this concept were patented and built as early as the turn of the century. In the early 1930s, about 120 wells in the mid-continent were provided with drainholes. In the early 1950s, drainholes were drilled in approximately 50 we11s; most were located in California (10). 


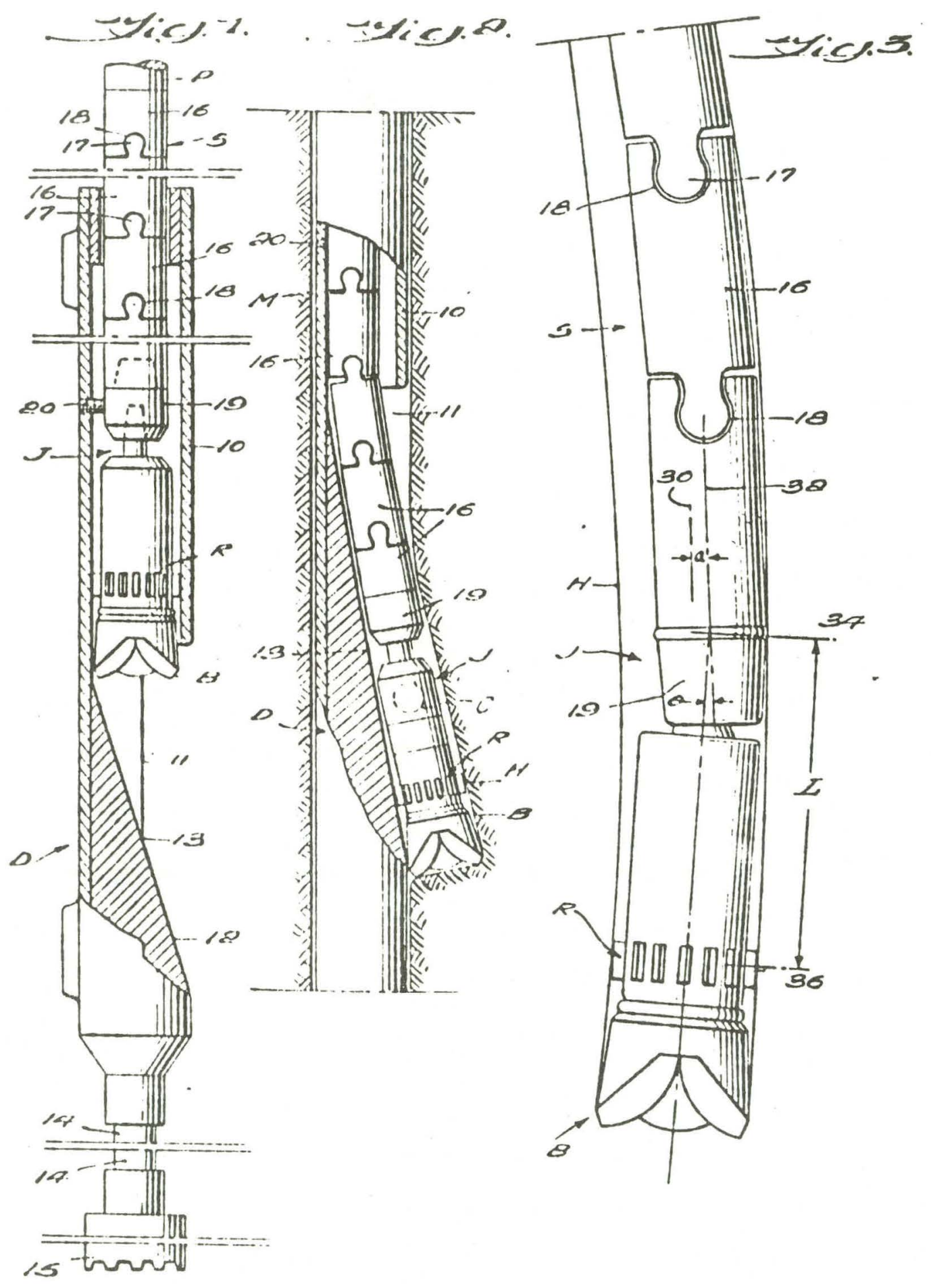

Figure 8. Holbert Drainhole Drilling Equipment 
STRAIGHT HORIZONTAL DRILLING

Discussions with mining engineers and a review of applicable patents indicate that horizontal drilling into coal seams is relatively new. The first drilling of this type was conducted in the U.S. in the early 1950s. In the early 1970s, Consolidated Coal Company began an intensive research effort to develop a drilling system which would drill into a coal seam, monitor the location of the bit, and guide the drill bit within the coal seam. The technique for loading the drill bit was only one aspect of their drilling research program.

Controlling hole direction is a major problem when drilling horizontally into a coal seam. Coal is soft and side loads on the bit can easily build hole angle. When bit thrust is generated outside the borehole and transmitted through drill pipe, the entire drill pipe can buckle as an Euler column within the confines of the borehole. Stabilizers and drill collars are therefore required near the drill bit to eliminate pipe buckling near the drill bit and to control drilling direction.

A discussion of the hardware developed to make horizontal drilling into coal seams feasible is presented in the following sections. Continental Mining Research has stimulated much of this hardware development. 


\section{Drilling Systems}

One innovative system for drilling horizontally into coal seams has been developed by Drilco. This system, designated the Kreepie Krawler and shown in Figure 9, is designed to provide an omni-directional drilling capability that is compatible with automation. It is made up of a downhole Dyna-Drill fluid motor and a downhole mechanical thruster. The unit is powered and controlled hydraulically through a bundle of hoses which serves as an umbilical to an external power source. The thruster unit has the capability to:

1. Apply axial force to the drili bit.

2. Grip the walls of the hole.

3. Walk the downhole unit either forward or backwards.

4. Apply lateral force to the drill bit for directional hole control.

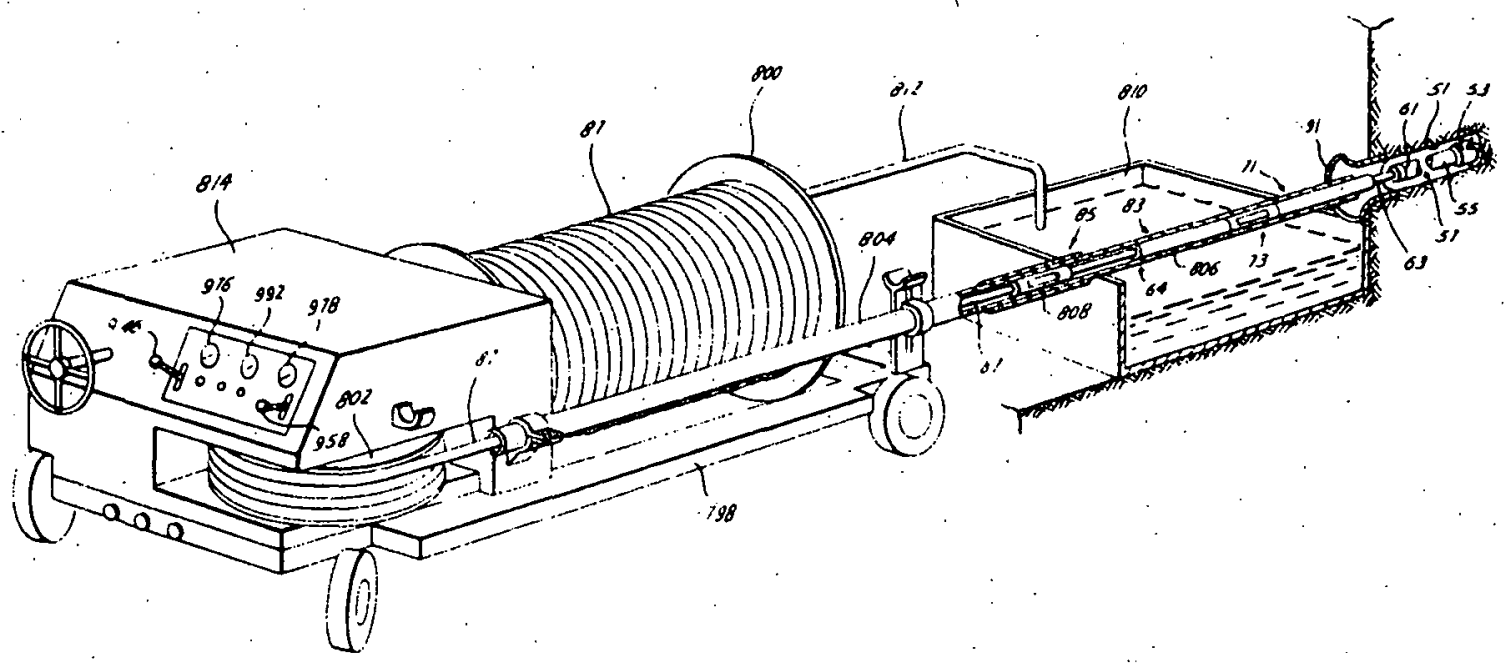

Figure 9. Drilco's Kreepie Krawler 
Drilco developed two different size thrusters: a 5-3/4" O.D. tool and a 2-3/4" O.D. tool. Both have been used to drill several thousand feet into coal beds. The maximum length for a single hole (6" diameter) was in excess of $700 \mathrm{ft}$. Some of the characteristics of the 5-3/4" tool are:

Outside Diameter

Length

Stroke

Power Required

Maximum Axial Thrust

Normal Drill Thrust

Normal Drilling Rate
$5-3 / 4^{\prime \prime}$

$128^{\prime \prime}$

$30 "$

$5 \mathrm{hp}$

$7000-80001 \mathrm{bs}$

$1000-40001 b s$

$200 \mathrm{ft} / \mathrm{hr}$

(occasional1y $1000 \mathrm{ft} / \mathrm{hr}$ )

Operational concerns with the "Kreepie-Krawler" are:

the hose spool is cumbersome and there may not be enough room in a 5 foot coal seam for, say, 2000-3000 ft of 3 inch hose bundle.

Another system for drilling horizontal holes at the coal face was developed by Acker Drill Company, Inc., of Scranton, PA (Figure 10). This system, which Acker labels "Big John" uses drill pipc to transmit rotation and axial force to the drill bit. It has the capacity to drill horizontally a distance of 3000 to $5000 \mathrm{ft}$. Downhole motors can be used in this drilling system, however, rotary power usually is delivered from outside the borehole.

A third mobil drilling rig was designed by Continental Oil 


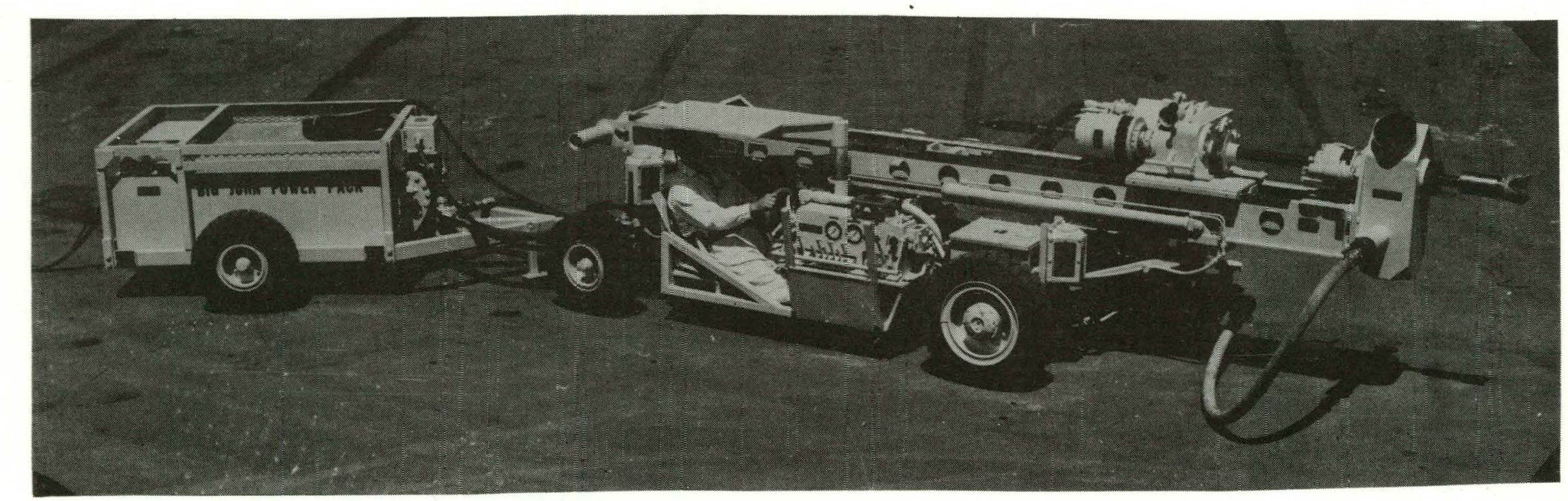

(Courtesy of Acker Drill Company, Inc.)

Figure 10. Ackers "Big John" 
Company and fabricated by J. H. Fletcher and Company of Huntington, WV. In this system, thrust is developed outside the wellbore and transmitted to the bit by drill pipe,

Bottomhole Assemblies

Stabilizers and drill collars that are required near the drill bit to insure borehole stability make up the bottomhole assembly (Ref. 1). There are two types of bottomhole assemblies being used with underground mobil drilling rigs which use drill pipe to transmit axial force to drill bits. One is called the rotary borehole assembly; the other the non-rotary borehole assembly.

The rotary borehole assembly contains two stabilizers separated by a 20 foot drill collar section; the drill bit is adjacent to the bottom stabilizer. The entire assembly rotates with the drill pipe. The purpose of the two stabilizers and drill collar is to control hole direction. Normally both stabilizers are used with an axial load of about 1500 t.n 1700 lbs applied through the drill pipe. If a directional survey indicates the borehole needs to be turned up, the back stabilizer is removed and the thrust is increased to about 2500 1bs. To turn the bit down, the front stabilizer is removed, and thrust is reduced to about $1000 \mathrm{lbs}$.

The non-rotary borehole assembly as proposed by Continental Oil Company includes a drill bit, deflection device or side thruster, downhole motor and stabilizer (11). 
"The deflection device is a spring-loaded, eccentric sub which exerts a constant force on the side of the bit. The direction of this applied force depends on the orientation of the device and determines whether the bit will be deflected up, down, left, or right. The magnitude of this force and hence the rate of angle build is controlled by the size of the spring." The advantage of this assembly is that it allows more directional control while drilling and provides non-rotating locations for downhole directional sensing instrumentation.

\section{Branch Drilling}

Branch drilling is a term used to identify a hole configuration having one or more sidetrack holes from a single vertical wellbore. This type of drilling has not been common in the U.S., although several have been drilled in recent. months. Branch wells such as the one shown in Figure 11 have been drilled at the Raft River (Idaho) geothermal site (12). The branch holes are not cased and are drilled as follows:

An 8-1/2 inch hole was drilled to $4342 \mathrm{ft}$ or approximately $100 \mathrm{ft}$ below the $9-5 / 8$ inch liner shoe. Directional drilling with Eastman Whipstock Services was initiated at this point. The hole drift angle was increased from $4-1 / 2^{\circ}$ at $4342 \mathrm{ft}$ to $8-1 / 2^{\circ}$ at $4395 \mathrm{ft}$ using a Dyna-Drill downhole motor. Conventional drilling was resumed and the first directional leg, RRGE-3A, was completed at a total depth (TD) of $5853 \mathrm{ft}$. Flow rate testing was conducted throughout the drilled interval. The second directional leg, RRGE-3B, was kicked off at $4524 \mathrm{ft}$ without setting a cement plug at the kick off point. 


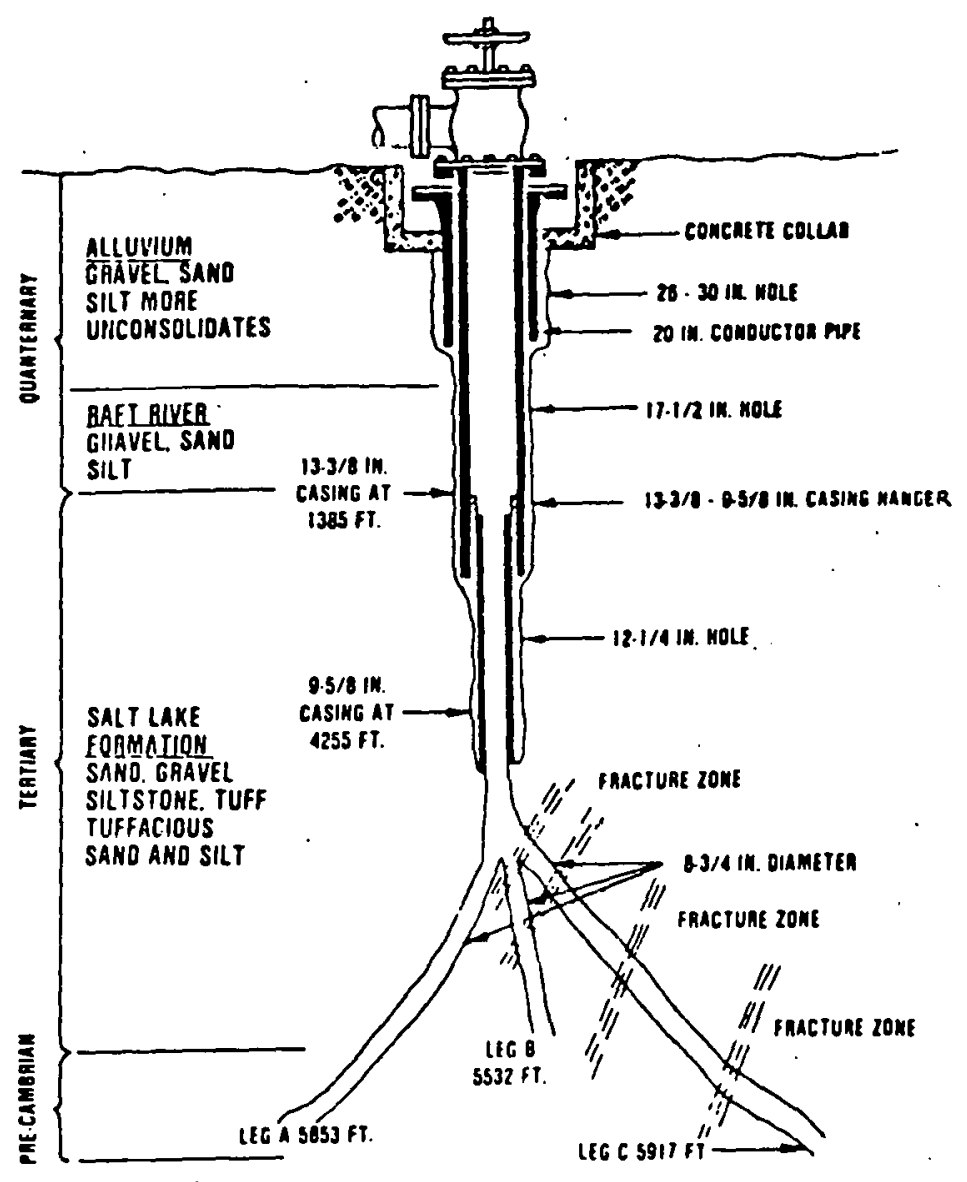

Figure 11. Branch Wellbore 
The desired drift angle of approximately $8^{\circ}$ was established after considerable difficulties. Conventional drilling was then used to complete the second $8-1 / 2$ inch hole to a total depth of $5532 \mathrm{ft}$. The horizontal separation between this leg (RRGE-3B) and the first directional leg (RRGE-3A) was $220 \mathrm{ft}$.

The final directional leg, RRGE-3C, was kicked off at $4332 \mathrm{ft}$. A drift angle of approximately $12^{\circ}$ was established before conventional drilling resumed and the 8-1/2 inch hole was completed at a total depth of $5917 \mathrm{ft}$. See Figure 11 for the relationships between the three directional legs (3A, $3 B$, and $3 \mathrm{C}$ ) .

The major problem encountered in branch drilling is the inability to selectively reenter one of the branched holes. 


\section{TECHNICAL NEEDS IN DIRECTIONAL DRILLING}

Although directional drilling itself is not new, technology often does not exist to meet requirements for increased resource recovery and increased cost effectiveness. The objective of this section is to enumerate some of the directional drilling needs and to relate the need to the resource objective.

Each of the functions of directional drilling (see Fig. 1). has numerous components. The mix of components and their specifications vary with each drilling situation. $\Lambda$ s discusscd previously, present directional drilling hardware and practice is based on drilling for conventional oil and gas. This technology for directional drilling for conventional resources has expanded greatly in the past decade with deep offshore oil and gas operations, and with expanded operations in populated and environmentally sensitive areas.

The necessity to develop unconventional hydrocarbon resources such as tar sands, heavy oil, methane from coal and others has increased the urgency and demand for improved directional drilling. Unconventional resources often require shallower, higher angle holes; targets are more exact; and hole configurations may be complicated. In addition, marginal resource production economics require lower cost drilling and lower risk drilling operations. 
Previous sections have set forth performance requirements (see Table I) for directional drilling and have discussed currently available technology. Critical needs exist.in all of the technology areas: bits, motors, instrumentation, downhole tools, fluids, and surface equipment. In general, the needs are common to both conventional oil and gas resources and to unconventional resources such as heavy oil, tar sands, oil shale, and others. Economic and risk factors may impact unconventional sources more frequently because of the magnitude of the resource and because of lack of operating experience. Directional drilling services presently applied in conventional oil and gas cost on the order of $\$ 5,000-\$ 10,000$ per day. This amount exceeds total daily drilling costs for some unconventional resources such as methane from coal; and as a result the service is not used.

Table II lists areas of possible research and development in directional drilling. Each topic is discussed below.

TABLE II

\section{$\underline{\text { RẸD Needs in Directional Drilling }}$}

Instrumentation

Sensors

Low Cost MWD

Surface Processing

Location \& Placement

Motors

Air and Foam Operated

Small Diameter, Light Weight Expendable

Reverse Drilling

Speed Controls
Drilling Fluids

Borehole Stability

Friction Reduction

Pipe Sticking

Cost and Maintenance

Hole Cleaning

Slurry

Augering

Viscous Slugging 


\section{TABLE II (cont.)}

\section{R\&D Needs in Directional. Drilling}

Bits

High Speed

Retractable

Sma11 Diameter

Weight-on-Bit

Thrusters

Conical Reamers

Wa11 Anchors

Hydraulic Loading

Hydraulic Pull-In

Decompression Subs

Rigs

Reelable Tubing

Flexpipe

Slant Hole

Percussion

Drill String Mechanics

Stabilization

Large Hole Systems

Slim Hole

High Angle Deviation Control

System Modeling
Drill in Casing

Rig Requirements

Expendable Motors/Bits

Cost Studies

Pipe Withdrawal

Pump-Out Systems

Wireline Assist

Steering

Variable Bent Subs

Reactive Torque Control

Feedback Systems

Water Jet Drilling

Short Radius Applications

Equipment and Procedures

Completion Systems

Branch and Drainage Holes

Kick-Off and Control.

Reentry

Completion

Length and Size Factor

Instrumentation needs to be developed that is a) more reliable, b) less expensive to build and operate, and c) more accurate. Improved MWD systems which are cheap and reliable are needed. This offers the greatest incentive for reducing drilling costs in non-typical directional wellbores. Reliability of sensors should be improved. New downhole sensors for measuring weight-on-bit, coal seam interface, bit condition, bit location, etc., are needed. Surface processing systems to acquire data and to interpret and display both surface and downhole measurements should be developed. Concepts for totally automated 
control and remote control should be explored. Capability for modeling the drilling process should be developed.

Equipment and techniques are needed to install directional surveying instruments and logging tools in high angle holes. Normally, these instruments are run in on a wire line. In high angle or horizontal holes, this is not possible.

Drilling motors to meet special requirements in directional drilling should be developed. High power, small diameter (less than 4") motors are needed. Concepts such as expendable or wireline retrievable motors should be investigated. A reverse drilling motor: might be considered in order to drill-in a controlled path pilot hole, then ream the hole to required size while pulling the pipe. Speed determination and control for motors would accelerate their utilization. Concepts for speed determination without special downhole packages and electronics need to be developed. Concepts for speed control should be investigated; for example, a heavy collar just above the bit might serve as a "flywheel," smoothing torque and speed variations and providing improved bit and motor performance. Motors operating on air or foam are needed.

Improved bits are needed to be compatible with the higher speeds of drilling motors and higher side loads in directional drilling. Small bits capable of higher sustained loads, and expendable bits could reduce costs. Applications for polycrystalline diamond compact bits should be investigated. 
Developing and maintaining weight-on-bit in shallow holes and in high angle holes is necessary to obtain reasonable drilling rates. Systems for hydraulic pull-in on shallow holes, especially those spudded non-vertically need to be improved. Alternative systems should be investigated, including possibilities of such techniques as wall anchors and hydraulic thrust across motors as a means of developing bit loading. Thruster systems need to be developed and tested for high angle and horizontal holes. Different systems may be required depending on the application, the formation, and the bit.

Rigs employing advanced technologies including flexible drill pipe, automatic pipe handling and spinning systems, high angle inclined spudding and others should be developed in order to reduce drilling costs, especially in nonconventional resources. Combination rotary/percussion systems should be studied. Consideration should be given to highly portable systems and to the maintenance and reliability of rig site equipment.

In planning high angle directional drilling programs, it is essential to design the bottomhole drilling assembly and drill string from basic engineering mechanics to avoid such problems as:

- Drill pipe breakage

- Locking or binding the downhole motor due to excessive hole curvature

$\therefore$ Inability to retrieve drill string 
- Inadequate bit force generation

- Excessive hole deviation

Drilling parameters which influence these operational problems are:

- Curvature of wellbore

- Radial clearance between drill pipe and wellbore

- Bottomhole assembly flexibility

- Collar stabilizer location

- Force applied to bit

- Horizontal distance to be drilled

Bottomhole assembly design data are needed for high angle and near horizontal directional drilling. A computer program should be developed to predict bending behavior of drill string assemblies in these types of wellbores. The program should be based on finite element methods with numerous coding options. A computer program is also needed to assist operators in evaluating different production schemes for enhanced oil recovery. This program would use system requirements as input and produce cost estimates, performance risk analyses, and drilling program outlines and schedules. The output would be based on accepted drilling formulas and a data bank of the performance parameters of all directional drilling equipment. Such a program would quickly tell whether or not a given production scheme is cost effective.

Drilling fluids are an area of continuing need. Borehole stability is a problem which can be controlled in many cases 
by the proper selection of fluids. Improved fluids can also reduce wall friction and drill string drag in directional holes, particularly high angle and horizontal. This will reduce string maintenance while increasing drilling capabilities. Problems such as lost circulation or handling of high water influx rates should be considered for those special cases where these problems occur. Guidelines need to be developed for formulating, building, testing, and maintaining the fluids used in high angle and horizontal holes.

Hole cleaning, traditionally a problem related to fluid type and flow rate, takes on special significance in directional drilling. Cuttings can fall to the bottom side of the hole allowing them to be bypassed by the fluid. New systems need to be considered and developed for cleaning of high angle holes. Approaches such as slurry systems, augering, partial gas 1 ift through bypass and other techniques should be considered.

Pipe withdrawal is a problem with increasing hole angle and with doglegs. Pipe which goes into the hole easily in compression can key-seat or become sidewall stuck when pulled in tension for withdrawal. Withdrawal systems including concepts for pumping the pipe out of the hole, using wireline assistance, reverse rotation, etc., should bc considered to solve this problem.

Drilling in with casing may reduce overall costs for many nonconventional operations. Special requirements including the capability of rotating larger pipe, handling increased weight, etc., 
need to be considered if such a system is to be developed. Feasibility of pulling in casing with pressure drop across a downhole motor or drill bit should be explored.

Steering of the drilling assembly is an essential component of a total downhole directional package. There are several types of bent subs presently being tested which would allow going into the hole straight and then activating the sub at bottom. The controls for these systems are electric, hydraulic pressure, wireline, etc. Present units should be tested. Additional ideas for such systems should be developed including the possibility of a totally remote system in which a target is programmed and the steering system will maintain the proper path toward that target. Also, mechanical steering tools located next to the drill bit would give better directional control.

Water jet drilling shows great promise in certain applications. Work has been done on branching horizontal holes at very small radii from a master hole in soft material such as coal. This type of work has particular application in the unconventional resources and possible applications for conventional oil and gas. Work needs to be extended to prove the systems that are in development; work should be done to delineate promising areas for new application. Systems should be devised to allow indexing and reentry of multiple holes while simplifying handling problems. 
Planning and equipment are keys to successfully drilling nontypical directional wells. In general, planning begins with system requirements such as 1 ithology, reservoir depth, wellbore configuration, etc. Equipment, tools, and operating practices are selected so that costs and risk are as low as possible. In most enhanced fossil fuel recovery programs, the margin for errors is small.

\section{CONCLUSIONS AND RECONMENDATIONS}

Directional drilling will play a significant role in the recovery of advanced fossil fuel reserves such as tar sands, shale oil, and coal. Actual wellbore configurations will be determined by such factors as resource type and location, production techniques, etc. Present directional drilling technology is inadequate to economically recover these resources. Therefore, it is necessary to adapt existing directional drilling practice and to develop new technology.

Specific directional drilling projects which will impact production of unconventional fossil fuel resources are:

- Develop engineering concepts and methods for maintaining bit weight in high angle holes.

- Investigate methods of controlling hole direction with bit forces which can be controlled from the surface.

- Develop directional surveying instruments and logging equipment that can be used in high angle wellbores. 
- Develop bit weight and motor speed sensor systems compatible with present motors and with present wireline and wireless MWD systems.

- Formulate software based on drill string mechanics for designing bottomhole drilling string assemblies in order to predict bit force, and to predict stress and deflection distributions in high angle wellbores.

- Investigate methods to enabie successful reentry of a specific borehole of a multiple bottomhole completion.

- Improve water jet drilling equipment and techniques.

- Develop methods for insuring borehole integrity, such as special casing designs.

- Determine the effects of vertical and side loads on the performance of downhole motors.

- Develop guidelines for formulating, building, testing, and maintaining fluids for drilling high angle and horizontal holes.

- Investigate methods of drilling smal1 radius drainholes.

- Test polycrystalline diamond compact bits on motors to determine torque requirements and drillability characteristics.

- Develop a system software model for establishing a cost effective directional drilling system (slim hole, large hole, high angle, stabilized, etc.) compatible with overa11 production scheme. 
- Perform detailed state-of-the-art technology review of automatic drilling rigs. Extend to computer controlled systems. 


\section{References}

1. Milheim, K., "Directional Drilling, Series of 8 articles appearing in The Oil and Gas Journa1, Nov. 6, 1978-Feb. 12, 1979.

2. "Introduction to Directional Drilling," Eastman Whipstock.

3. API Recommendations for Directiona1. Drilling Survey Caiculation Methods.

4. Eberts, R. D. and R. D. Barnett, "Ultrahigh-Angle Wells are Technical and Economical Success," The 011 and Gas Journal, July 19,1976 .

5. Lyons, E. P. and O.. E. Mechan, "THUMS Refines Directional Drilling Technology," World Oil, September 1968.

6. Bezaire, G. E. and I. A. Markiw, "Esso Resources Horizontal Hole Project at Cold Lake," Petroleum. Society of C.IM, Paper Number 79-30-10.

7. Shuck, L. Z., J. Pasini, III, J. W. Martin, and L. A. Bissett, "Status of the MERC In Situ Gasification of Eastern U.S: Coals Project," Proceedings of Second Annual Underground Coal Gasification Symposium, Morgantown, West Vịginia (1976).

8. Diamond, W. P. and D. C. Oyler, "Directional Drilling for Coalbed Degasification. in Advance of Mining," U.S.B.M. Methane Recovery from Coalbeds Symposium; Pittsburgh, PA, Apri1 1979 .

9. Holbert, D. R., "Method of Drilling a Curved Bore," U. S. Patent No. 3,398,804, August 27, 1968.

10. Stormont, P. H., "Increasing Drainäge of Oil Into We11 by Drain-Hole Drilling," The Oil and Gas Journal, August 17, 1953.

11. Thakur, P. C. and W. N. Poundstone, "Horizontal Drilling Technology for Advance Degasification," Preprint No. 79-113, presented at the 1979. AIME Meeting, New Orleans, February 18 22,1979 .

12. "Raft River Geothermal Exploratory Hole No. 3," RRGE-3 Completion Report, June 1977, IDO 10069 (NVO-410-40). 


\section{$\underline{\text { References (cont.) }}$}

13. Kellner, J. M. and A. P. Roberts, "Hydraulic Wall-Anchored Drill Collar Promises Lower Drilling Costs," The Oil and Gas Journal, Vol. 58, No. 40, October 3, 1960 .

14. Bradley, W. B., C. E. Murphy, R. T. McLamore and L. L. Dickson, "Advantages of Heavy Metal Collars in Directional Drilling and Deviation Control," JPT, May 1976.

15. Hook, R. A., L. W. Cooper, B. R.. Payne, "Air, Mist and Foam Drilling: A Look at Latest Techniques," World Oil, Apri1 1977 .

16. Rehm, W. A., "State-of-the-Art Study - Directional Drilling," MEI Report No. TR77-18, for Sandia Laboratories, July 1977.

17. Garrett, W. R. and H. M. Rollins, "New Deviation Control Looks Good in Field Tests," World Oil, October 1964.

18. Deily, F. H., D. W. Dareing, G. F. Paff, J. E. Ortloff, and R. P. Lynn, "Downhole Measurements of Drill String Forces and Motions," J. Eng. Ind. (May 1968) 217-225, Trans ASME 90.

19. Denison, E. B., "High Data-Rate Drilling Telemetry System," JPT, February 1979.

20. McDonald, W. J., and C. E. Ward, "Borehole Telemetry System is Key to Continuous Downhole Drilling Measurements," The Oil and Gas Journa1, September 15, 1975 .

21. Ideco, 1978/79 Genera1 Catalog.

22. "Unique Rig Uses Flexible Drillstem and Electric Motor," World Oil, May 1964 .

23. "Flexodrill Development Nears Successful Completion," World 0.il, July 1977 . 


\section{STATE-OF-THE-ART OF DIRECTIONAL DRILLING ELEMENTS}

Present techniques and capabilities for directional drilling systems have been developed over the years for use in the petroleum industry. Early uses were to straighten crooked holes and to side track lost tools.. The most frequent current use is to direct the path of the borehole to a predetermined bottom-hole location.

This section gives a review of both conventional and nonconventional directional drilling equipment and serves as background for the main body of the report.

\section{Drill Bits}

Rotary drilling is based on the tricone rock bit. Both roller bearings and journal bearings are used in these bits. The roller bearings usually last from 20 to 50 hours: whereas the sealed journal bearings last from 50 to 200 hours.

These bits operate effectively at speeds of 50 to 200 . RPM whereas existing drilling motors operate at speeds of 300 to 1,000 RPM. At these high motor speeds, the bit bearings fail in 5 to 15 hours. This short life usually precludes using roller bits with motors for straight hole drilling since bit runs of 50 to 200 hours are needed to be competitive with rotary drills in this application.

The problem of short bearing life can be overcome by developing lower speed motors and developing higher speed bits. Both approaches should be taken to optimize the use of drilling motors and to accelerate their application. 
The development of high speed roller bits which will operate for 50 to 100 hours at bit weights of 4,000 to 8,000 pounds per inch hit diameter and at speeds of 150 to 250 RPM is needed. These bits coupled with motors designed to operate at these speeds would have a significant impact on domestic drilling costs. These motors could potentially produce 10 to 15 percent savings in the $\$ 15$ billion domestic drilling costs.

Oil field diamond bits are currently used at speeds of 50 to $200 \mathrm{RPM}$ on rotary rigs and at speeds of 400 to 1,000 RPM with drilling motors. Diamond bits last from 100 to 200 hours on motors and therefore do not require major improvements for widespread use on motors.

Diamond bits used on high speed turbodrills are designed for high flow rates and low bit pressure drops.

The fluid courses on the high speed bit are much larger than those on the conventional bit for two reasons (1) the turbodrill requires higher flow rates and (2) the seals in the turbodrill limit the fluid pressure drop across the bit. Curved fluid courses are used on the turbodrill bit in an attempt to obtain more fluid crossflow between the diamonds. This is done in an attempt to overcome the lower pressure drops across these bits.

Because of torque and motor bearing limitations, diamond bits are usually run at lower bit weights on turbodrills than with rotary rigs. Fewer diamonds are usually used on the turbodrill bits in order to obtain the same loading per diamond with the lower bit weights. 
General Electric has developed new manmade diamond cutting

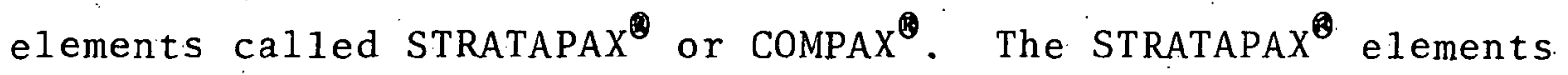
are small discs containing a layer: of diamond on a tungsten carbide substrate. The STRATAPAX ${ }^{\circledR}$ contains a dense, sintered, polycrystalline. diamond layer which has a hardness slightly below that of natural diamond. The hardness is considered above that of tungsten carbide used in drag bits or roller bits.

Drilling rates of $190 \mathrm{ft} / \mathrm{hr}$ have been obtained with the STRATAPAX ${ }^{-}$bits compared to maximum rates of $120 \mathrm{ft} / \mathrm{hr}$ with diamond bits. The STRATAPAX bits perform best at speeds of 200 to 400 RPM whereas rotary rigs can normally operate at speeds up to only 150 RPM. STRATAPAX bits are, therefore, ideally suited for use with downhole motors. For this reason, emphasis should be placed on developing STRATAPAX bits for use with drilling motors.

Water jet drilling is being pursued by Sandia National Laboratories as an alternative method for drilling horizontally from the bottom of a vertical borehole. Its cutting action is developed from fluid momentum changes. A conceptual layout of the water jet drilling system is shown in Figure 12. A principle feature is the ability to turn small radius corners. This feature would permit easy rotational indexing for full $360^{\circ}$ multiple completions from a single vertical borehole. 


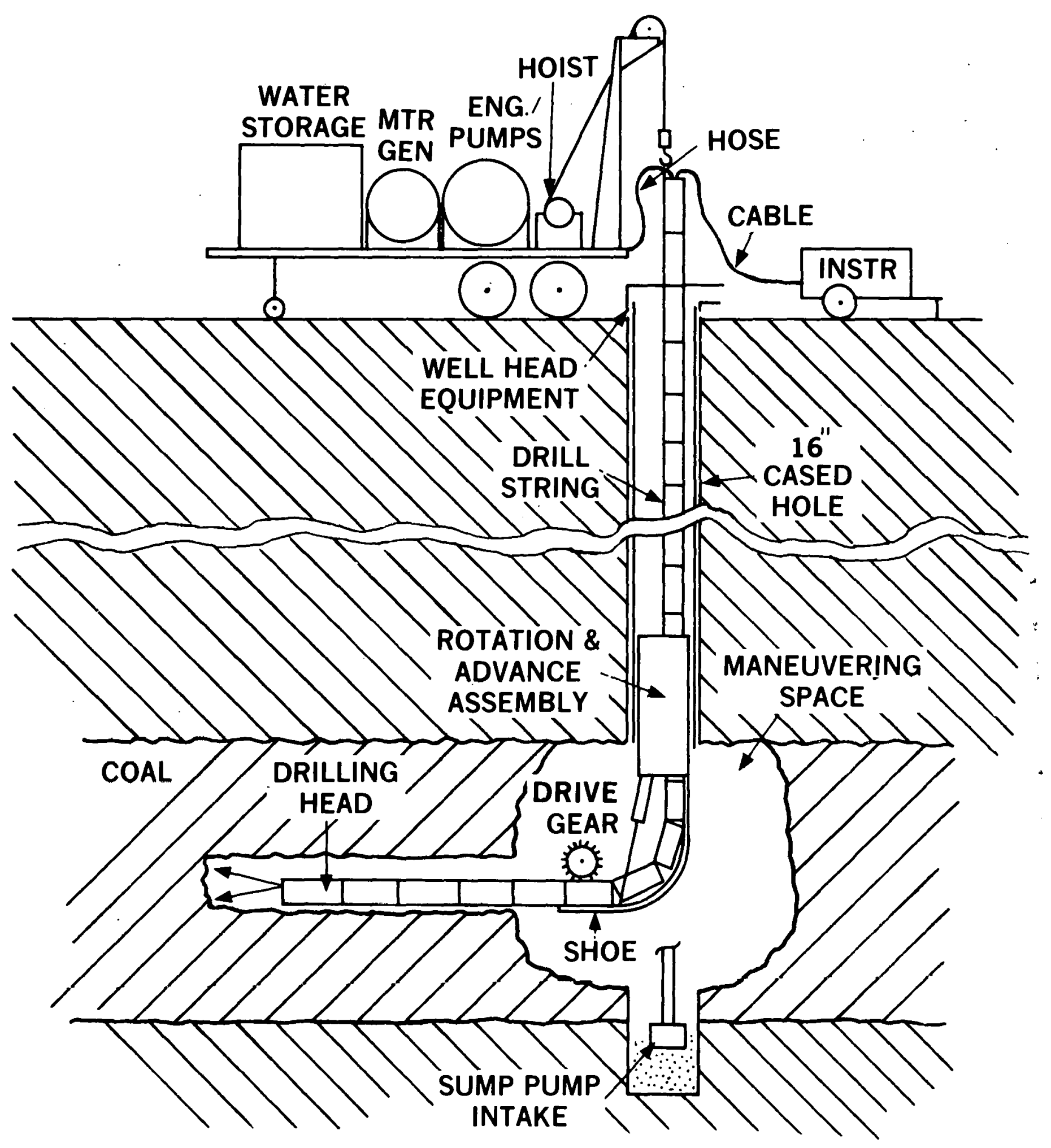

Figure 12. Water Jet Drilling System Layout 


\section{DRILL BIT THRUSTERS}

Since the early days of rotary drilling, bit force or bit weight has been generated by gravity (e.g., drill collar weight). Drill collars are heavy walled tubulars located directly above. the drill bit and apply their weight to the drill bit when tension support at the top of the drill string is reduced. Drill collars are simple and rugged. Their length is designed to generate the desired bit weight while keeping the neutral point within the collars. This keeps the drill pipe from buckling.

The use of drill collars has not been completely satisfactory. Drill collars are much heavier than drill pipe and thus increase hoisting and rig floor handling requirements. In addition, drill collars deflect laterally due to their weight and this deflection changes the orientation of the drill bit and causes the borebole to deviate. Stuck drill strings in the borehole are often attributed to the presence of drill collars; however, this problem is alleviated by using spiral drill collars. Also, the length of drill collars frequently prevents their use in drilling through hard formations lying very close to the earth's surface.

Downhole wall anchors are an alternative to drill collars, but they are not regularly used by the petroleum industry. They fit into the drill string directly above or near the bit and derive their downward force by fluid pressure acting on cylinders. The magnitude of the downward thrust force depends on the pressure drop across the drill bit and on the cylinder pressure area. Multiple cylinders can increase the total pressure area and thus bit force magnitude. The reaction thrust is taken by grippers that 
expand against the walls of the wellbore. Gripping capacity is an important design consideration because it must be as great as the downward bit thrust.

A. P. Roberts invented a wall anchor tool in the late 1950's (11). One disadvantage of this Exxon patent is that drilling has to be stopped and pump pressure lowered to disengage the anchor blocks so that the tool can be reset for the next drilling interval. This disadvantage is overcome by other Exxon patents that followed as they allow for automatic reset. A prototype of this type was built and tested and has worked for 17 automatic resets (see Figure 13).

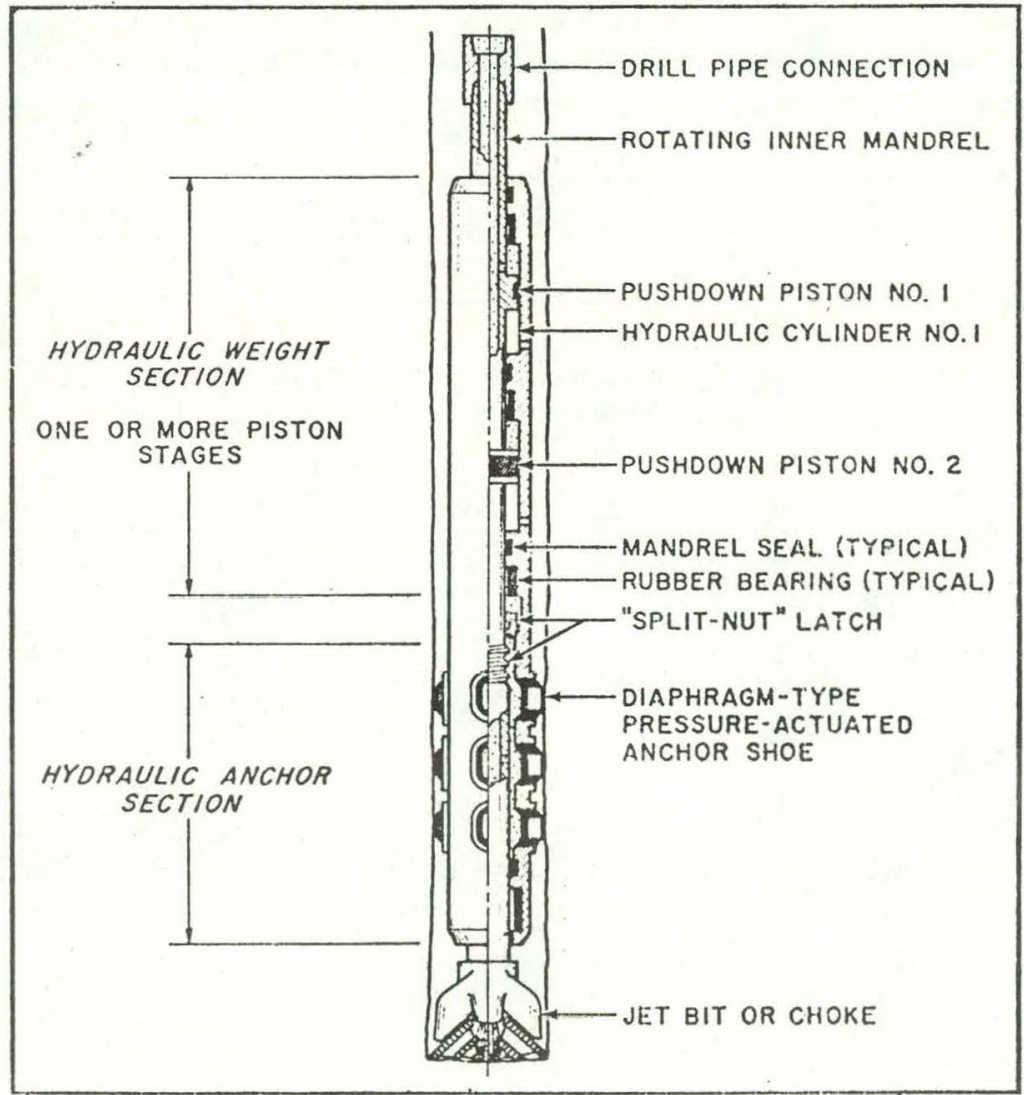

Figure 13. Exxon's Wa11 Anchor 
Another type of thruster is described in Patent Number 4,060,141 and is part of a self-propelled turbine drilling system (Figure 14). This thruster is made up of expandable "clam shells" which grip the borehole, an axial turbine propulsion unit, and a screw drive. The downward thrust, or bit force, is generated by a turbine which operates essentially at stalled torque conditions, advancing the drill bit and a separate drill turbine via the screw drive; thrust reaction is transmitted to the borehole walls by the "clam shells." When the screw drive reaches the end of its travel, the thrust turbine is reversed allowing the thrusting device to follow the cutter head.

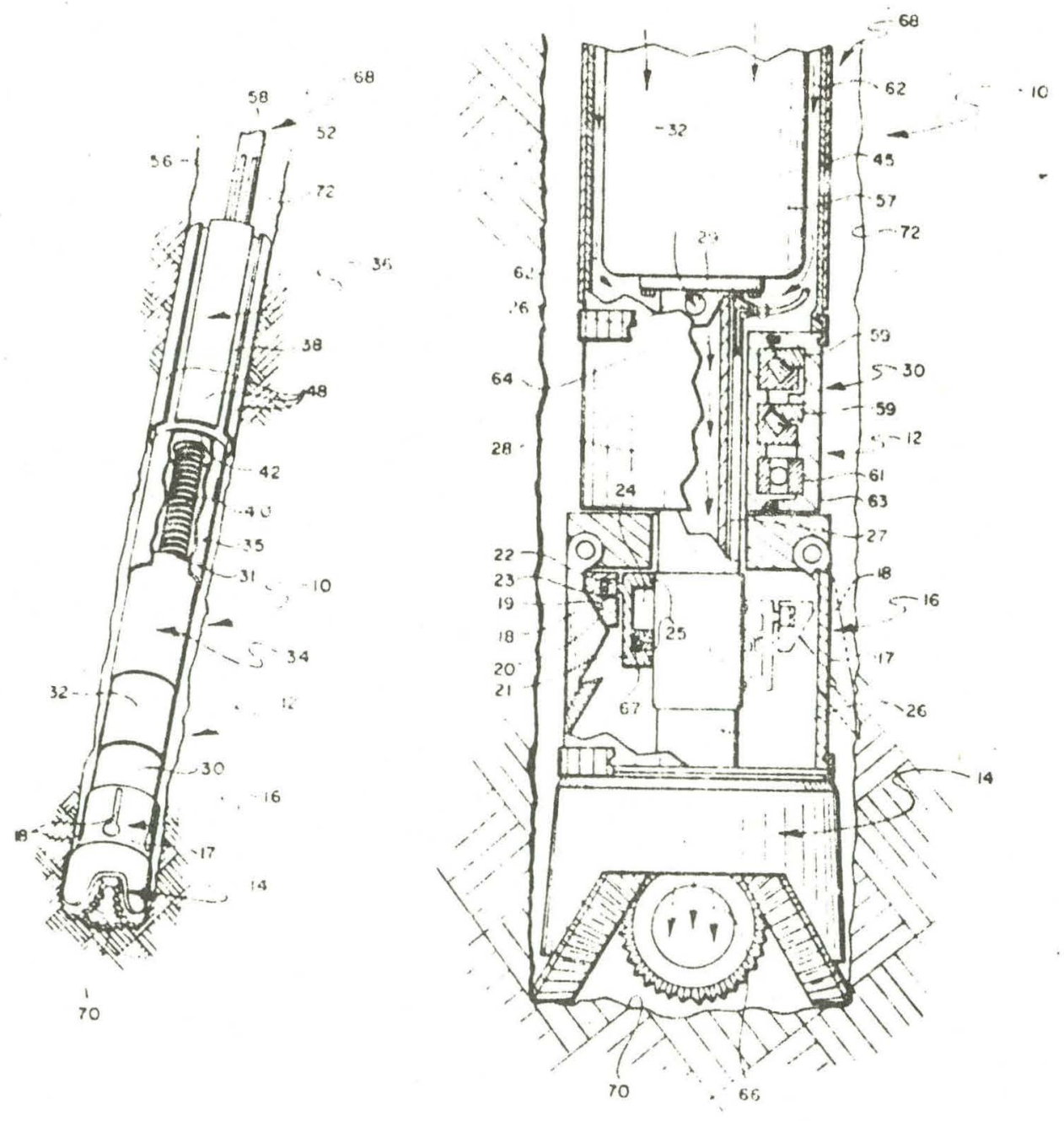

Figure 14. Drill Bit Thruster 
Carey E. Murphy, Jr., of Shell Oil Company patented a heavy metal collar concept and analytically showed that his idea would improve drilling practices by providing more well deviation control in difficult formations (see Figure 15). By using depleted uranium or tungsten as drill collar material, the collar section would be stiffer, heavier, and shorter than normal steel collars (13).

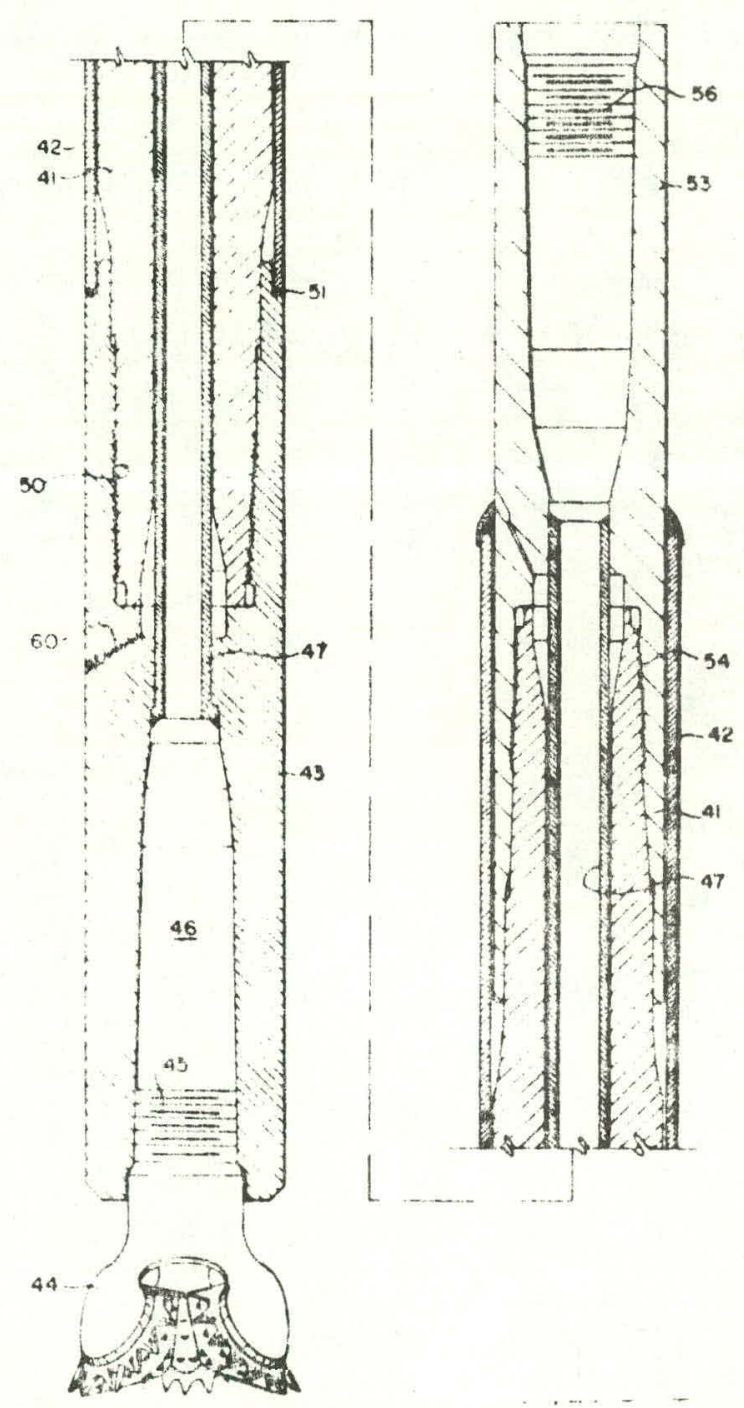

Figure 15. Heavy Metal Drill Collar 
The thruster types mentioned so far generate static bit forces. A. G. Bodine, Jr., patented a dynamic force generator for developing dynamic forces at the drill bit (Figure 16). His patent describes various types of mechanical devices for exciting the longitudinal vibration modes of drill strings in order to generate, dynamic forces at drill bits. Experiments showed drilling rates of 6 inches per minute in granite with the Bodine apparatus compared to one inch per minute with conventional rotary drilling methods.

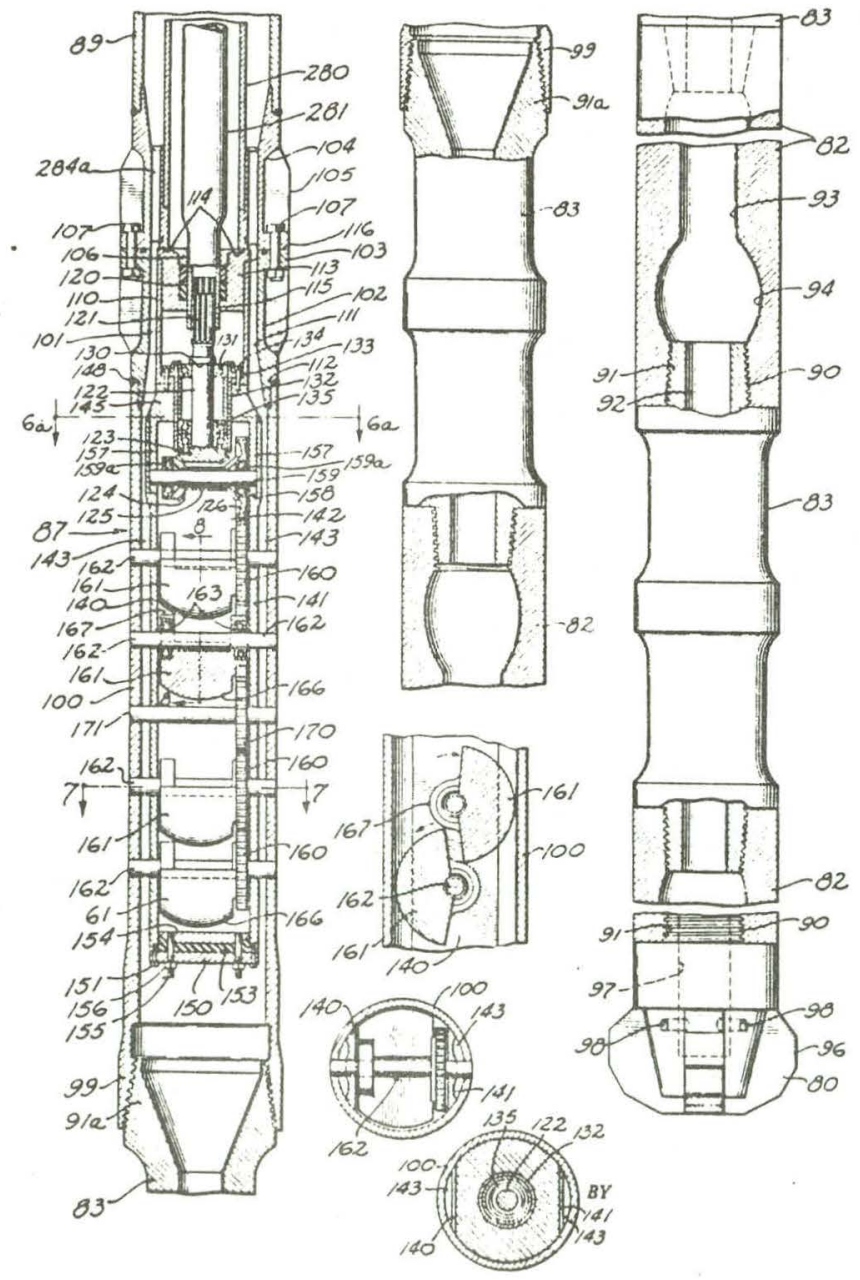

Figure 16. Bodine's Dynamic Force Generator 
Air percussion hammers are used in certain formations to maintain a straight hole and achieve a reasonable penetration rate while running 1 ight weight $(1,000$ to 5,000 pounds) on the bit (14). Water-bearing formations, however, create problems for air drilling. In a typical application, a rotary percussion drill turned about 40 to $50 \mathrm{rpm}$ while hitting about 800 strokes per minute. According to one rough rule of thumb, 2,000 to 3,000 lbs of weight is equivalent to 30,000 lbs of collar weight. Conversion of conventional rotary rigs to an air drilling operation is simple. Most liquid and solids handling equipment normally used for mud drilling can be removed. Air compressors are available which provide adequate air volumes along with portability. The most commonly used oil field air compressor is a positive displacement, double acting, reciprocating, two or three stage unit.

\section{STEERING TOOLS}

The main forces acting on the bit are pendulum forces of gravity, levered forces of the drill string, the wedging or refraction effect of formation changes and the walking effect of rotation, especially of the tricone bit (15).

These forces are controlled by:

1. Adjusting bit weight - Lighter bit weights encourage the bit to drill in the direction it is pointing. High bit weight turns the hole and helps build hole angle. Very light bit weight produces low penetration rate but makes it casy to control the direction of the well. 
2. Using large drill collars or square drill collars The stiffness of a pipe is proportional to the fourth power of the diameter. So stiffening drill collars by increasing their diameter is very significant. Square drill collars are often used to obtain adequate stiffness and still allow room for fluid circulation.

3. Placing stabilizers in the collar string - Stabilizers can be placed to control the action of the lower part of the drill string according to either pendulum or lever principles. Two stabilizers are used to maintain hole direction; the bottom stabilizer relieves the transverse bit force component.

One stabilizer directly above the bit is used to build hole angle. This method of building hole angle is based on the fulcrum principle as shown in Figure 17 and requires adjustment in bit weight to tilt or lever the drill bit about the fulcrum point.

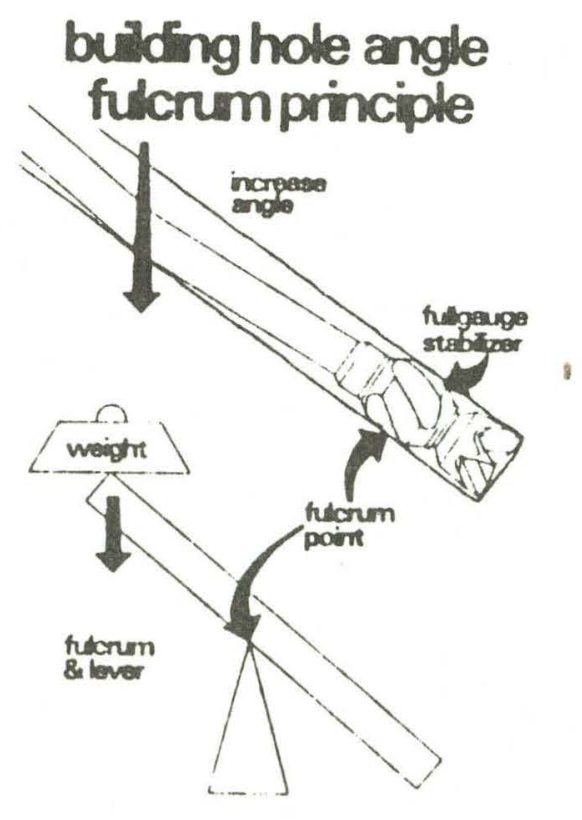

Figure 17. Fulcrum Principle 
Hole angle can be decreased by using one stabilizer as shown in Figure 18. This stabilizer acts as a pivot point for a drill collar pendulum. Restoring bit forces are generated by drill collar gravity loads which tend to swing the collars and bit back to the vertical position.

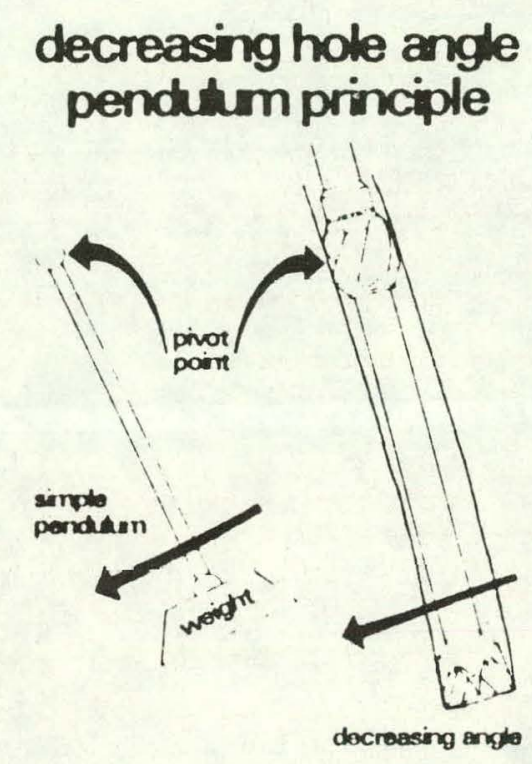

Figure 18. Pendulum Principle

The bent sub is a preferred directional tool wherever it can be employed. The bent sub, which may be a bent downhole motor housing, can thrust the bit off at an angle (Figure 19) when used with the proper collars and stabilizers. Orientation of a hent sub 
can give $360^{\circ}$ of azimuth change by indexing the drill pipe. It can also give changes in angle and/or direction. Bent subs normally are made up in $1 / 2$ degree angles to four or five degrees.

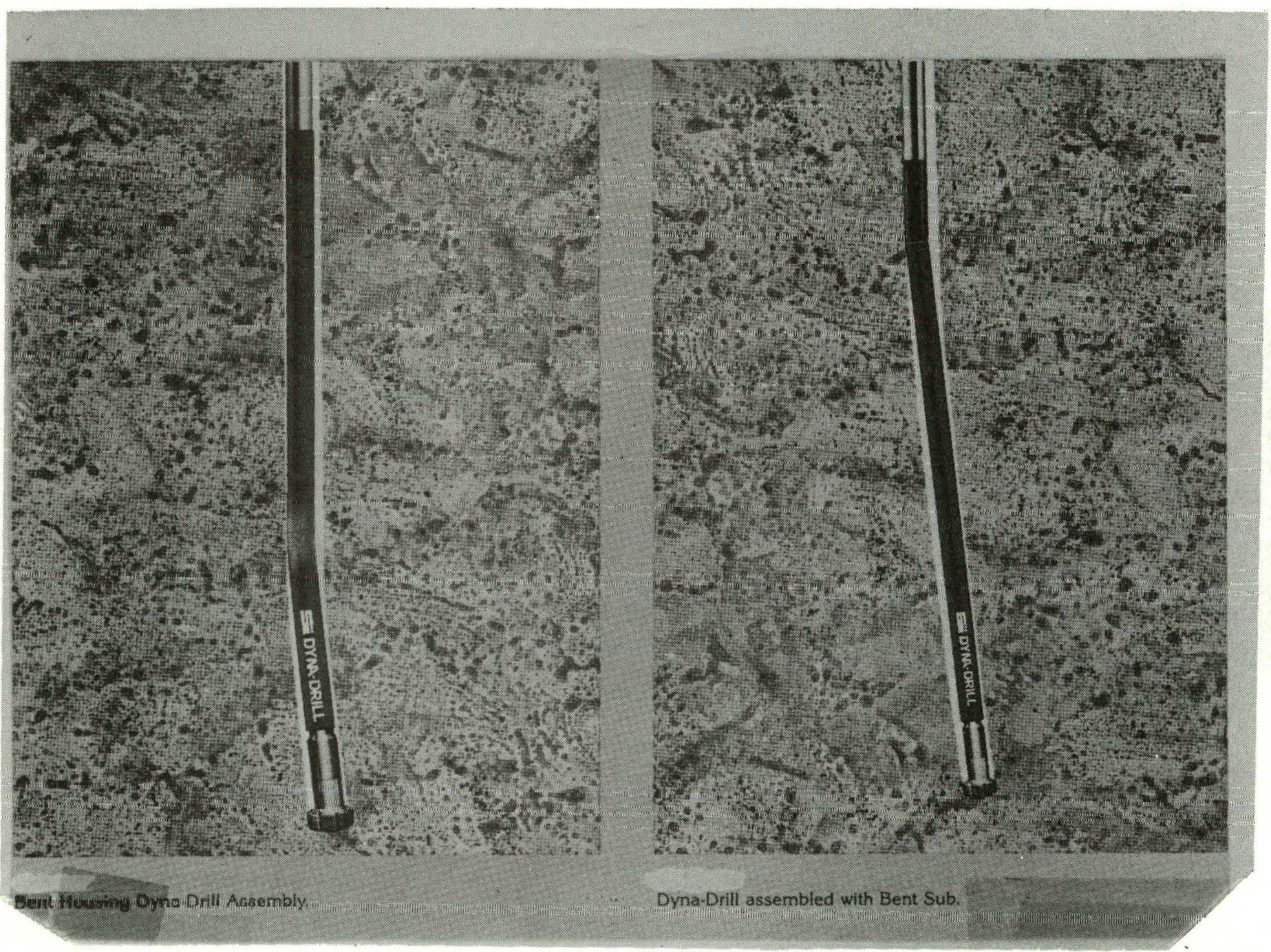

Figure 19. Bent Sub and Housing 
The bent sub technique is limited to drilling when using a downhole motor because the obvious advantages of the bent sub are lost if the drill pipe must be rotated. The bent sub does not provide enough directional/side thrust to drill out of casing when sidetracking a hole or to change direction across the grain of a hard rock with very strong anisotropic properties. The Dyna-Drill Division of Smith Industries markets a variable bent sub (Figure 20). It is wireline actuated and cannot be used when a mule shoe orientation collar is in use. This severely limits its use. The development of a variable sub that can be used with steering tools could reduce directional drilling costs by $25 \%$ by eliminating extra trips. 


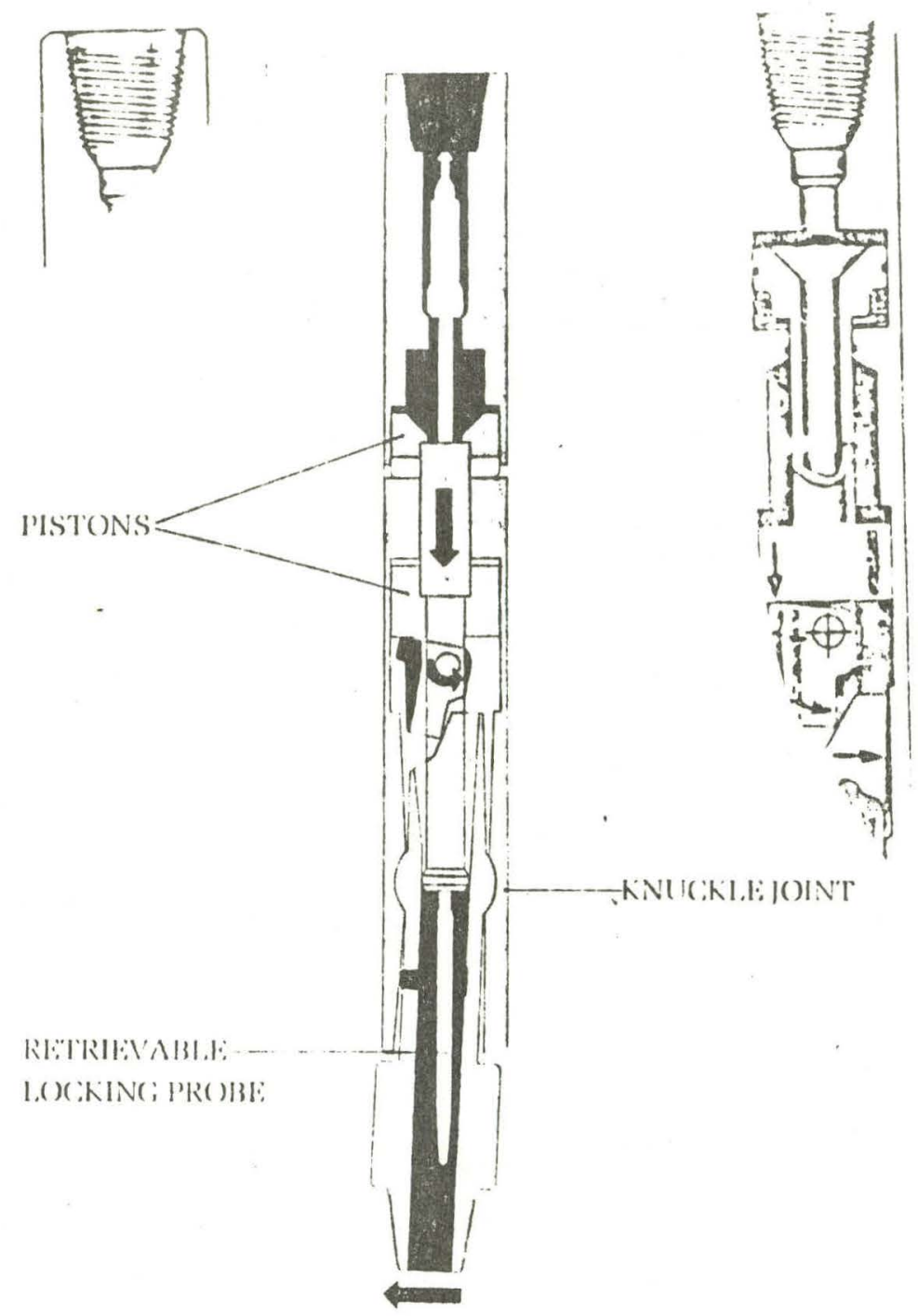

I)YNA-FILK

Figure 20. Dyna-Flex Sub (Dyna-Dri11, 1977)

The directional drilling service business was founded on the whipstock. (Figure 21). It is a rugged and reliable tool, but consumes a lot of rig time. The tool is a wedgeshaped steel casting with a tapered concaved guide channel for the bit. 


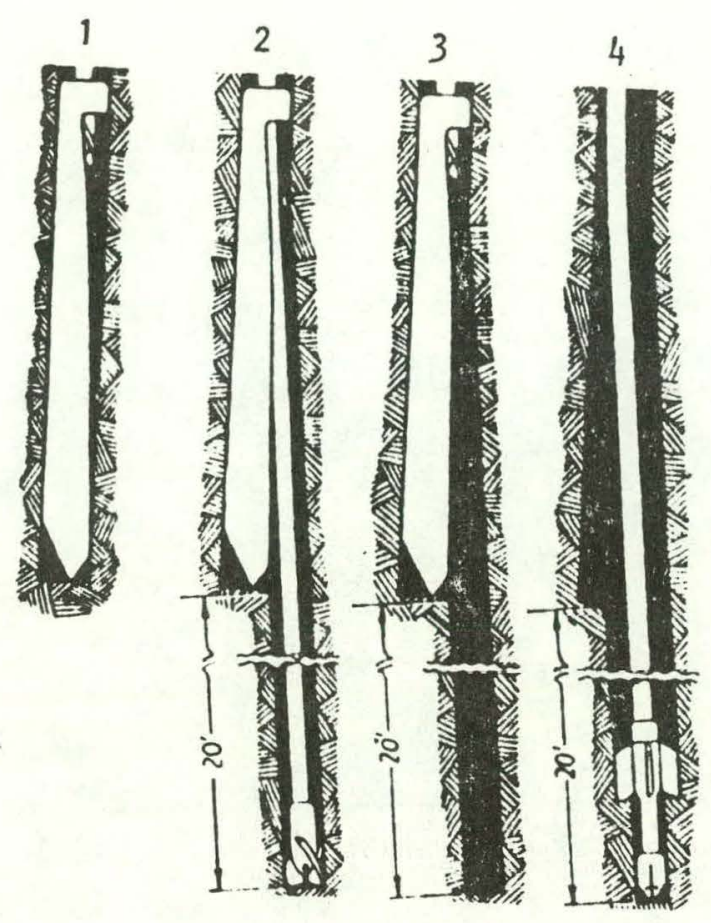

1. Set the Whipstock

2. Drill Pilot Hole

3. Remove Whipstock

4. Ream Pilot Hole

Figure 21. Whipstock Steps

The use of the whipstock requires many round-trips for on $1 y$ a smal1 amount of hole obtained; thus, is usually much more expensive than the jetting and Dyna-Drill techniques. The whipstock should only be used in situations where the other two techniques cannot be employed. Drilco developed a downhole thruster tool called a "Bit Boss" which has the capability of generating both transverse and axial bit forces. The tool can be used either as a directional drilling tool by forcing the drill string laterally against the wellbore or it cril lie uned as a wall anchor for applying axial thrust to the 
drill bit. The positioning members or guide shoes are activated hydraulically by removing a valve by wireline. Drill collar weight is needed for drilling until the tool is activated by retrieving the valve. A single pressure source is common to al1 positioning members. The positioning members in their directional tool are in a non-symmetrical pattern which is oriented within the wellbore to produce the desired transverse movement against the wellbore. The anchoring cylinder is stationary within the wellbore and the inner pipe rotates and advances with the drill bit.

Positioning members in Drilco's wall anchor tool are symmetrical and centralize the tool within the borehole. Downward bit thrust is developed by pump pressure acting on internally exposed shoulders. The inner pipe rotates and adyances with the drill bit. These tools are fully developed and commercially available.

During the early $1960^{\prime} \mathrm{s}$, Drilco built and tested a side thruster for use in deviation control (16). Their thruster was marketed and used during a short period of time. Operational steps are illustrated in Figure 22. Field experiences obtained with this tool are

- "The tool has been operated to depths as great as 10,000 feet. Conditions creating unusual torque or drag on the drillstem tend to limit the depth at which the tool can be run with best results."

- "No difficulty has been experienced with oversize hole preventing the shoes from engaging the hole wa11. Apparently, there is not substantial hole enlargement just above the bit even in very soft formation." 
- "Extra rig time required to operate the tool including running surveys, setting the sleeve and replacing worn parts has varied from one to four hours per day."

- "Although this tool is believed to be of general utility for all drilling fluids, including air and gas as well as water and oil base muds, the particular design herein described was built specifically to operate in a hole drilled with normal drilling liquids."

- "A full-time operator is required to supervise the drilling crew in use of the tool and to provide local inspection and maintenance of the tool."

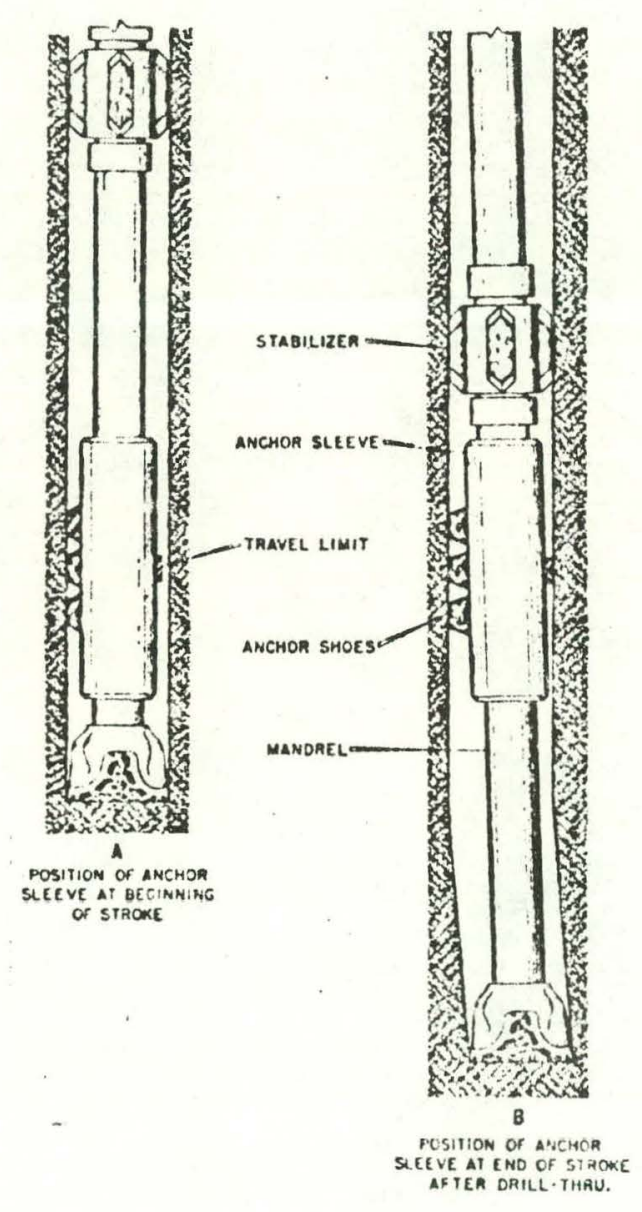

- Basic concept of the new tool is the hydraulic jack effect of the anchor shoes when drilling.

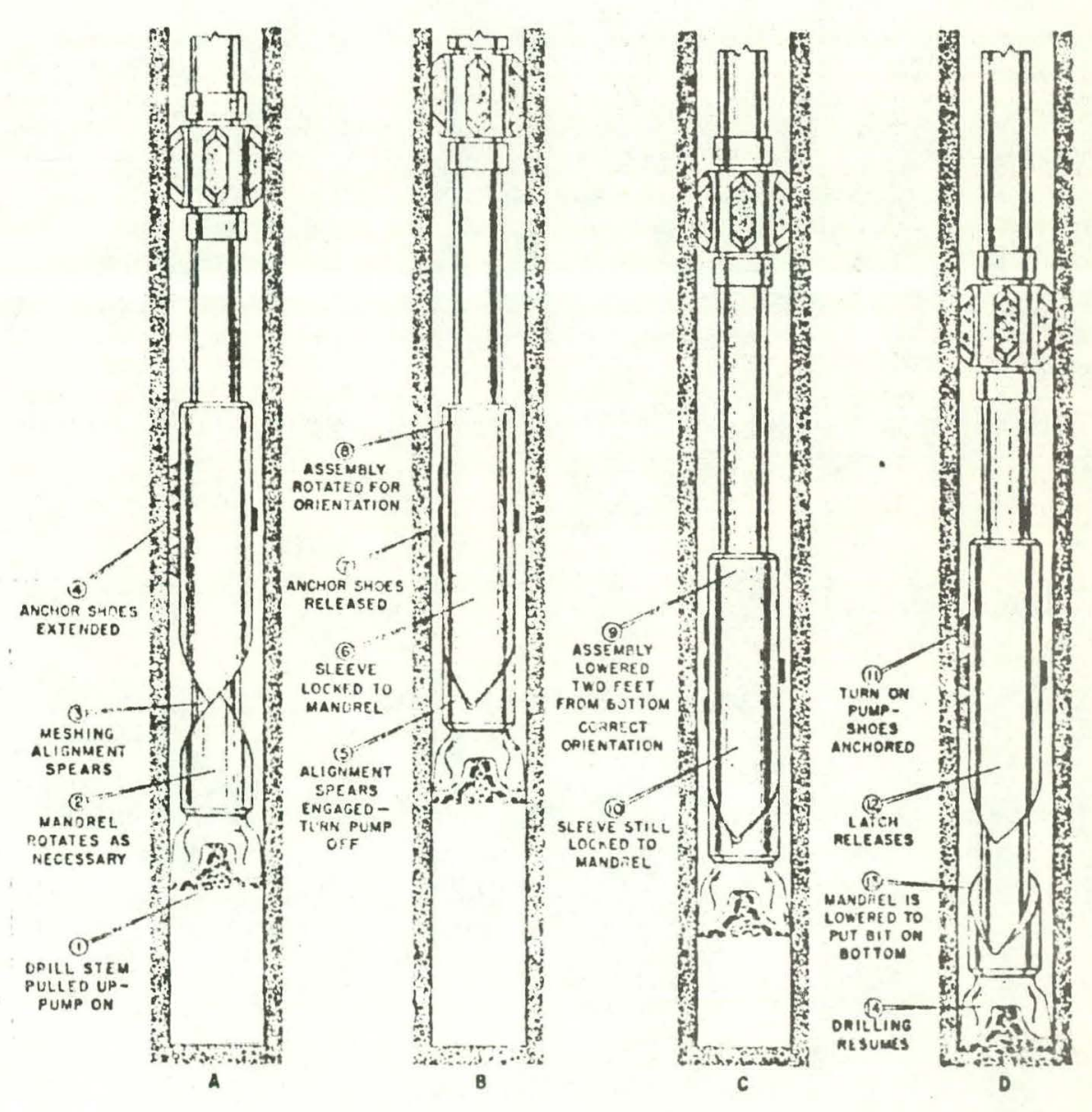

-Detailed operation of the new directional control tool is shown above in sequence views $A, B, C$ and $D$.

Figure 22. Drilco's Thruster 


\section{DOWNHOLE DRILLING MOTORS}

\section{Positive Displacement Motors Positive displacement motors}

have the distinct advantage that the rotary speed is directly related to the pump flow rate. The flow rate is therefore a direct measure of the rotary speed of the motor.

In addition, the torque delivered by the positive displacement motor is directly proportional to the pressure drop across the motor. The rig mud pressure gauge can therefore be used to monitor bit torque.

The Dyna-Drill Moineau Motor, marketed by Smith International, is shown in Figure 23.
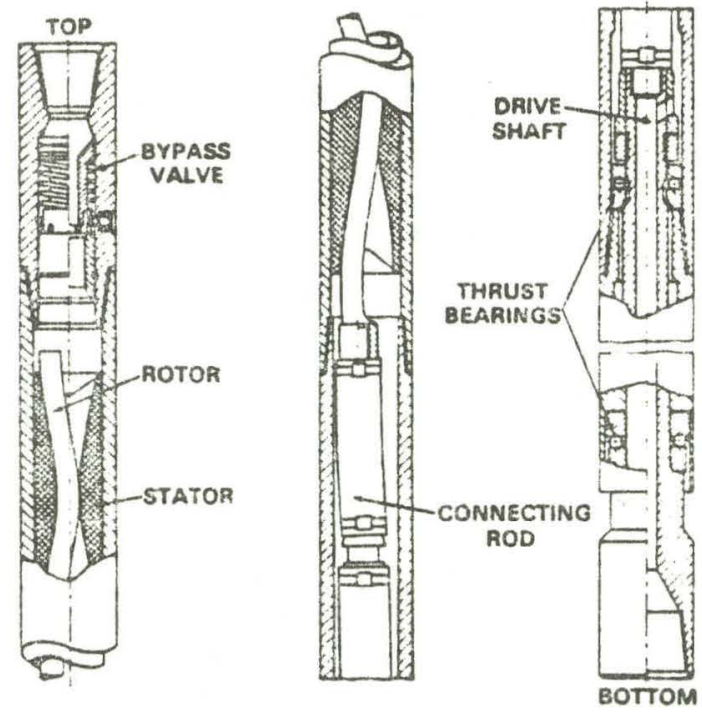

Figure 23. Dyna-Drill Moineau Motor

The multi-stage motor consists of an eccentric steel shaft rotating in a rubber housing. As fluid is pumped through the motor, the fluid acts on one side of the rotor, tending to rotate it and the bit. The stator is molded from Buna $N$ rubber to resist abrasive wear and the steel rotor is chrome plated to reduce wear. 
A radial marine bearing is used as a flow restrictor. This radial bearing allows 5 to 10 percent of the mud to flow through the ball bearings to cool and lubricate them with the remainder of the mud entering the drive shaft and exiting through the drill bit.

When drilling with bent subs, it is important that short motors be used in order to prevent bending of the motors. DynaDrills have the advantage that the motor housing can be bent at the connecting rod housing. This allows the hole direction to be changed in some applications.

Table III

DYNA-DRILL OPERATING CHARACTERISTICS

(Dyna-Drill, 1977)

$\begin{array}{ccccccc}\begin{array}{c}\text { Outer } \\ \text { Diameter } \\ \text { (in) }\end{array} & \begin{array}{c}\text { Motor } \\ \text { Length } \\ (\mathrm{ft})\end{array} & \begin{array}{c}\text { Flow } \\ \text { Rate } \\ (\text { GPM) }\end{array} & \begin{array}{c}\text { Pressure } \\ \text { Drop } \\ \text { (psi) }\end{array} & \begin{array}{c}\text { Available } \\ \text { Torque } \\ \text { (ft-lbs) }\end{array} & \begin{array}{c}\text { Power } \\ \text { Output } \\ \text { (HP) }\end{array} & \begin{array}{c}\text { Rotary } \\ \text { Speed } \\ \text { (RPM) }\end{array} \\ 7-5 / 8 & 26.4 & 600 & 250 & 1,080 & 72 & 350 \\ 6-1 / 2 & 21.0 & 400 & 250 & 700 & 41 & 310 \\ 5 & 19.6 & 325 & 250 & 467 & 36 & 410 \\ 3-3 / 4 & 19.7 & 225 & 250 & 283 & 25 & 460 \\ 2-3 / 8 & 17.6 & 130 & 170 & 127 & 10 & 420 \\ 1-3 / 4 & 9.7 & 25 & 595 & 24 & 4 & 375 \\ & 7.9 & 20 & 425 & 16 & 2 & 800\end{array}$


Turbodrill Turbodrills utilize axial flow turbine blades to apply torque to the drill bit as shown in Figure 24.

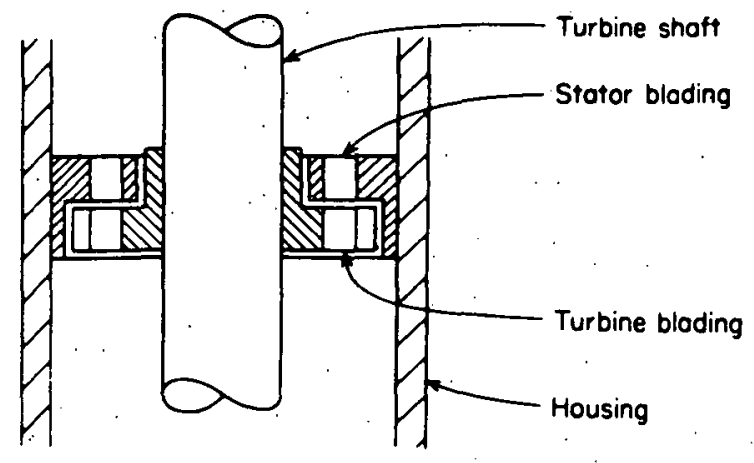

Design of single-stage section in turbodrill

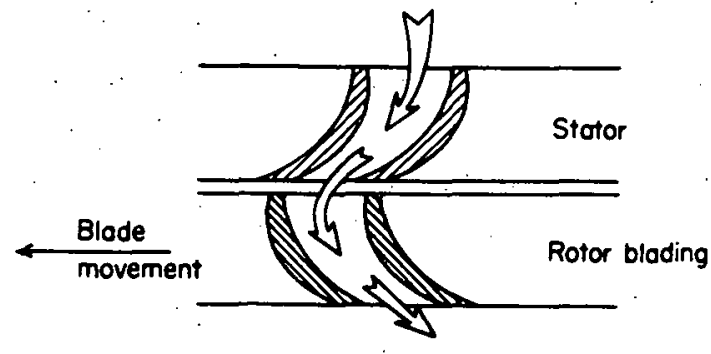

Typical cross section of turbine bloding showing the flow of fluid through one stoge of the unit

Figure 24. Turbodrill Blading

The torque developed by a turbodrill is maximum when the turbodrill stalls. Torque can be increased by increasing the number of turbine stages, by increasing the fluid flow rate or by increasing the exit angle of the turbine blades. Torque decreases from a maximum at the stall condition to zero at the runaway speed. The turbodrili delivers maximum power output at 50 percent of the runaway speed.

The runaway speed of oil field turbodrills is typically 1,000 to 2,000 RPM so these turbodrills deliver maximum power output at speeds of 500 to 1,000 RPM. This high rotary speed results in short bearing life in roller bits; consequently diamond bits are usually used on turbodrills. The high speed of Dyna-Drills ( 300 to 500 RPM) also results in short bit bearing life with roller bits. 
Electrodrill Electrodrills utilize 3-phase synchronous electric motors to power the bit. The speed of these synchronous motors is directly related to the frequency of the electric current: The speed of the motor can be infinitely varied by varying the frequency of the current. This allows the driller to monitor and control the rotary speed of the motor, an important advantage over turbodrills.

The synchronous motors are operated at constant voltage; consequently, the motor torque is proportional to the electric current. The current meter on the rig floor is a direct measure of the bit torque. This allows the driller to continuously monitor the bit torque and to adjust bit weight (i.e., bit torque) to optimize the drilling conditions. This is an advantage over turbodrills where the torque is unknown. "The power output of the motor is proportional to the producl of frequency and current.

Although downhole electric motors have desirable operating characteristics, they have not found widespread use because of problems encountered with handling and maintaining the electric cable in the drill pipe. Most electrodrills utilize electric cables permanently mounted in the center of the drill pipe. This precludes running tools down the inside of the drill pipe to log or when problems occur such as stuck drill pipe. This is a major disadvantage which led to abandonment of a German electrodrill project. New systems are being considered where 
the cable is reelable or where it is mounted on the inside wall of the drill pipe, thereby overcoming this major limitation. Electrodrills have the advantage that the electric cable can be used as a communication link from the bit to the surface. This allows transmission of data to the surface while drilling. An electrodrill is being developed by General Electric for this purpose.

\section{DOWNHOLE ' SURVEY INS'I'RUMEN'I'S}

Downhole survey instruments, used to establish wellbore configuration, measure two angles: (1) drift or angle from vertical and (2) azimuth or orientation of wellbore tangent from North. Drift and azimuth measurements at two successive locations along with the arc length between these two locations are used to calculate wellbore configuration in geospace. Overall wellbore configuration and drill bit location are tracked from periodic surveys.

The azimuth or direction of the hole can be obtained from either a compass or a gyro tool. If a compass is used, the survey must be in the open hole away from the influence of the casing. A monel drill collar (or several monel collars) is used as a landing base for the magnetic tool.

The magnetic survey instrument takes several different forms, but in general; it includes the compass rose floating in a liquid, a film disk, a light, and a timer. The timer is set on the surface and the instrument either dropped in the hole or run in on a wire line: When the tool gets to bottom, the timer turns the light on 
and a picture is taken of the compass rose which is tilted in the direction of hole deviation. In another system a ball rolls on a cup-shaped compass rose to indicate direction.

The gyro operates much the same as the compass for direction. In some tools, the gyro is coasting and in others it is energized. Multishot tools are also available that use a roll of film and a timer. They may be run or dropped in the hole and will take pictures at preset intervals.

The measurement of hole angle or drift is mechanical using camera and electronic devices to record the results. Normally, both drift and azimuth are recorded or photographed together. Early devices showed only drift angle with a mechanical punch; these devices are not used in directional drilling today. Steering tools, or dynamic measuring systems give a continuous dircction and angle readout while drilling with a downhole motor (Figure 25). The information is at present sent to the surface by means of a wireline. This requires that the line and tool be retrieved for each connection. The sensors used are completely different from the conventional one shot and multishot systems.

Angle is established by body-fixed transducers. The transducers have their measuring plane established by the plane of the instrument body established by the course of the borehole. This scheme measures the components of input angle rather than total angle. These components must be processed to determine the total angles. 
This processing is done in the surface equipment which is not necessarily limited in physical size. Measurement of the components of the earth's magnetic field by body-fixed, fluxgate transducers is not influenced by the extreme shock forces encountered by drilling situations.

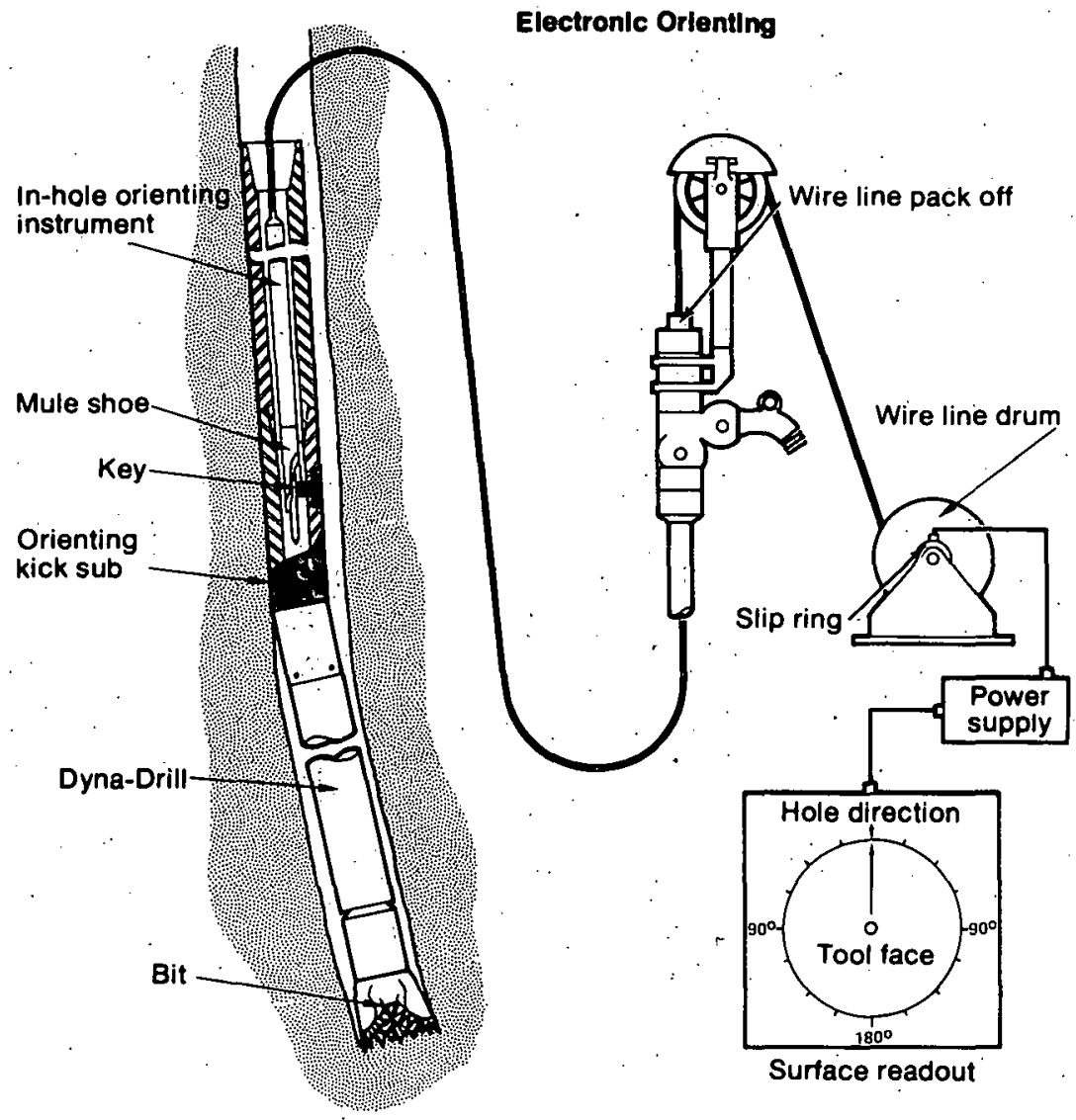

Figure 25. Steering Tool Layout

Flux-gate transducers are similar in construction to a transformer. Physically, a flux-gate element consists of a mumetal rod around which a coil of wire is wound.

In operation, when the axis of the mumetal rod is placed in a magnetic field, it will acquire a certain flux density by induction. Flux density may be measured by applying an alternating magnetic field. Flux-gate assemblies are generally arranged physically such that a differential measurement is made. Again, the processing is done in the surface processer unit. 
The instrument pack is run on the end of a single cable and is locked into orientation with the bent sub by means of an orienting groove - a mule shoe orienter.

The entire system allows the steering of the drill bit by rotation of the drill string and bent sub as a result of the mud motor reverse torque. When the bit is pushed into the formation, the reactive torque rotates the bent sub and changes hole angle and direction. This is read immediately at the surface readout as direction and angle. By loading or relieving the bit, the bit can be steered, and the initial general orientation is established by rotating the drill pipe at the surface to make the downhole tool face the proper direction.

Conoco has developed borehole survey instruments for measuring drill bit azimuth, pitch, rol1, and coal thickness (10). The latter indicates the thickness of coal between the horizontal borehole and the floor, or the roof, depending on the orientation of the survey tool. The surveying probe is a 1.8 in 1 ong, $43 \mathrm{~mm}$ diameter cylindrical housing which contains a triaxial magnetometer for the azimuth measurement, two accelerometers for pitch and roll, and a sensor for weak gamma radiations from the roof and floor of coal seams.

There are no commercially available sensors for monitoring weight on bit while drilling. This information is needed especially in high angle holes where frictional forces are significant and where the weight indicator at the rig floor cannot give bit weight directly, During the early 1960'3, Exsull (EPRCÓ) developed a 
downhole recording instrument package for measuring dynamic bit forces (17). Data was recorded on a magnetic tape within the self-powered package and played back after the tool was retrieved. Shell has also developed downhole sensors for measuring drill bit motions while drilling (18). Their system transmits downhole information through an armored cable contained within the drill pipe.

Telemetry Although several methods and applications to retrieve downhole data have been studied (including radioactive and chemical tracers, drill pipe vibration and torque, and downhole recorders), there are four basic types of systems which show promise as communication and transmission methods (19). These are:

- Mud pressure pulse

- Wireline or insulated conductor

- Electromagnetic waves

- Acoustic methods

1. Mud Pressure Pulse. In this system, the resistance to the flow of mud through the drill string is modulated or pulsed by means of a valve and control mechanism mounted in a special drill collar sub near the bit (Figure 26). The pressure travels up the mud column at near the velocity of sound in the mud, about 4,000 to $5,000 \mathrm{ft} / \mathrm{sec}$. The rate of transmission of measurements is relatively slow due to pulse spreading, modulation rate limitations and other limitations characteristic of mud systems.

In the mud pulse unit, the power source for telemetering data is the pressure field developed by the mud pumps on the 
surface. Modulation of the mud pressure is accomplished downhole and power for modulation of the mud pressure must be available downhole. While mud pressure can be used to cock springs or cams. as in the Teledrift system, most advanced systems use either batteries or a mud turbine generator. Mud pressure pulse should not be confused with acoustic systems, which do not depend on having the pumps running to transmit the signal.

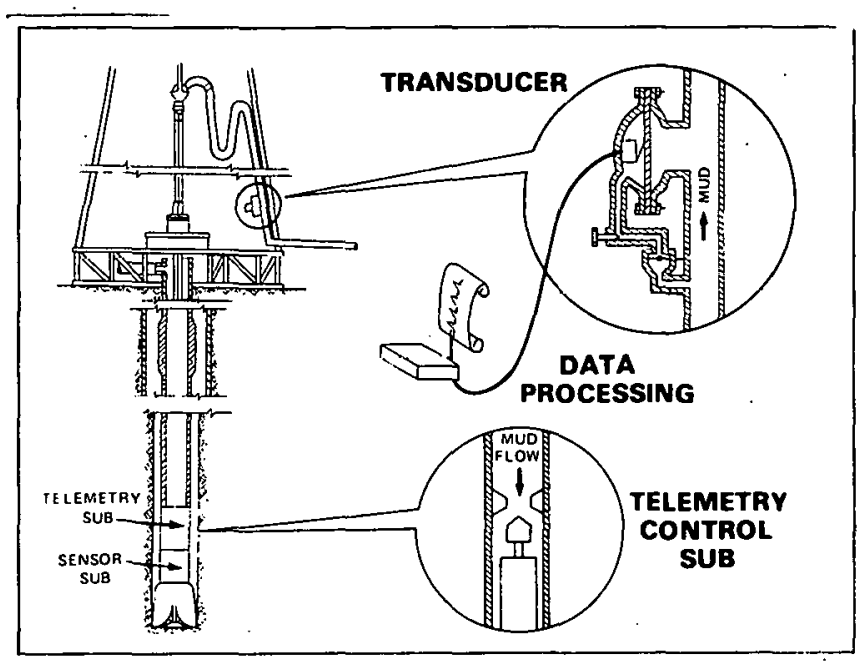

Figure 26. Mud Pulse System

The inherent advantages of the mud-pressure pulse concepts are that neither insulated cables nor special drill pipe are required. Power for the system is derived from the mud stream. The systems are basically mechanical and should be reliable. The primary disadvantages are that the system has a relatively slow data rate and the signal must be extracted from a fairly noisy enviromment. The "mud siren" has a higher data rate, but (at least in current versions) requires a downhole power generator, thus incurring problems in cost and reliability relative to some simpler forms of mud pulsing systems. Sensor systems presently in use require cessation of drilling during acquisition of directional data. 
2. Electromagnetic Waves Transmission of electromagnetic (EM) signals both through the earth and/or drill pipe has been studied as a telemetry method for downhole measurements while drilling (Figure 27). Numerous companies have worked on EM systems; many of these investigations were on government contract relating to coal mine safety or to military applications. With the EM method, a relatively high data rate may be possible, and there is no need for special drill pipe. There are several possible disadvantages. Only very low frequency EM signals have low enough attenuation for transmission through the earth to be feasible. Unfortunately, these frequencies are near telluric frequencies. Thus, background noise makes detection and information recovery with the EM signals very difficult.

Attenuation of the EM signals on drill pipe also limits application of this approach. Repeaters would add cost and reliability problems. An EM system would probably have the disadvantages of requiring a downhole power generator.

In addition, it is not clear that ali EM systems are applicable offshore, a necessary condition for general commercial application.

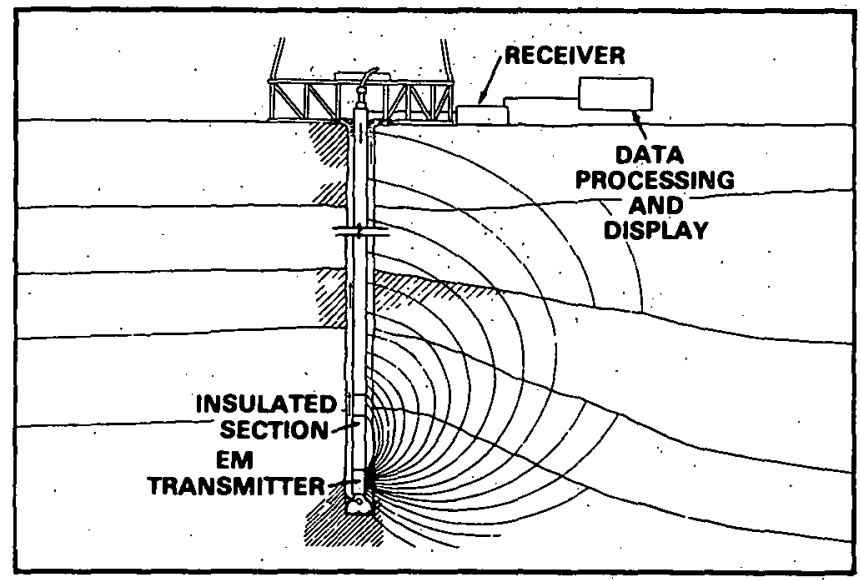

Figure 27. Electromagnetic Wave System 
3. Wireline Systems Insulated conducter systems are present1y used for logging and other borehole operations. The adaptation of the electrical conductor or hardwire system to a continuous drilling operation would solve the borehole telemetry problem (Figure 28). However, problems associated with connecting and maintaining such an electrical line under rotary drilling conditions have not met requirements for an easy to use, economical, and reliable system.

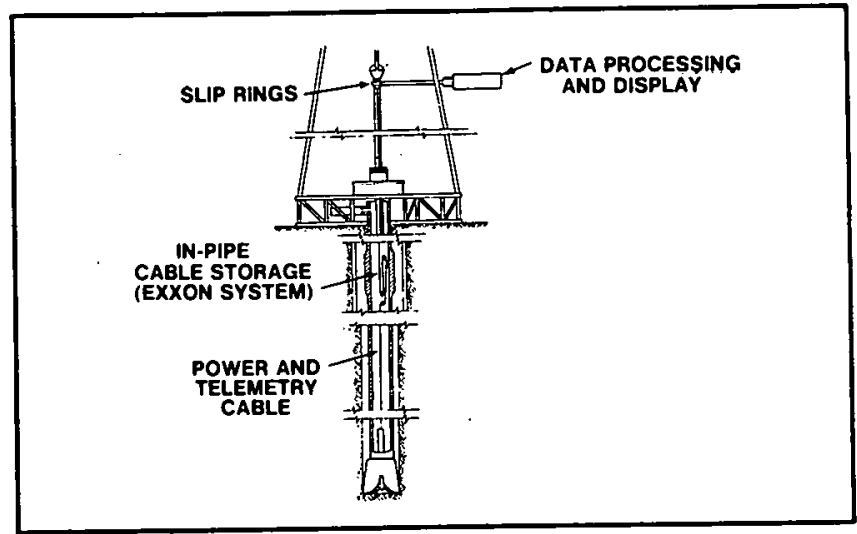

Figure 28. Exxon Electrical Telemetry

Major advantages to a hardwire system are that data rate can be extremely high, two-way communications are simple and electrical power can be supplied over the conductor system.

Disadvantages include cost reliability (especially of connectors), wear and failure of cable due to mud abrasion and pipe rotation, potential interference with fishing operations, and requirements for special equipment and supplies such as cable handing reels and non-conductive compounds. 
4. Acoustic Methods Another potential method for borehole telemetry is by transmission of acoustic or seismic signals through the drill pipe or the earth (Figure 29). As discussed earlier, acoustic systems should not be confused with mud pressure pulse systems. Acoustic systems do not depend on having the mud pumps running for signal transmission.

The very low intensity of the signal which can be generated downhole, along with the acoustic noise generated by the drilling systems, makes signal detection difficult. Reflective and refractive interference resulting from changing diameters and thread makeup at the tool joints compounds the signal attenuation problem.

The primary advantages to acoustic systems seem to be simplicity and cost, but the important disadvantage is that high signal attenuation and acoustic noise are generated in the drilling limit range. Repeaters incur reliability and cost problems, and downhole power consumption could present another difficulty.

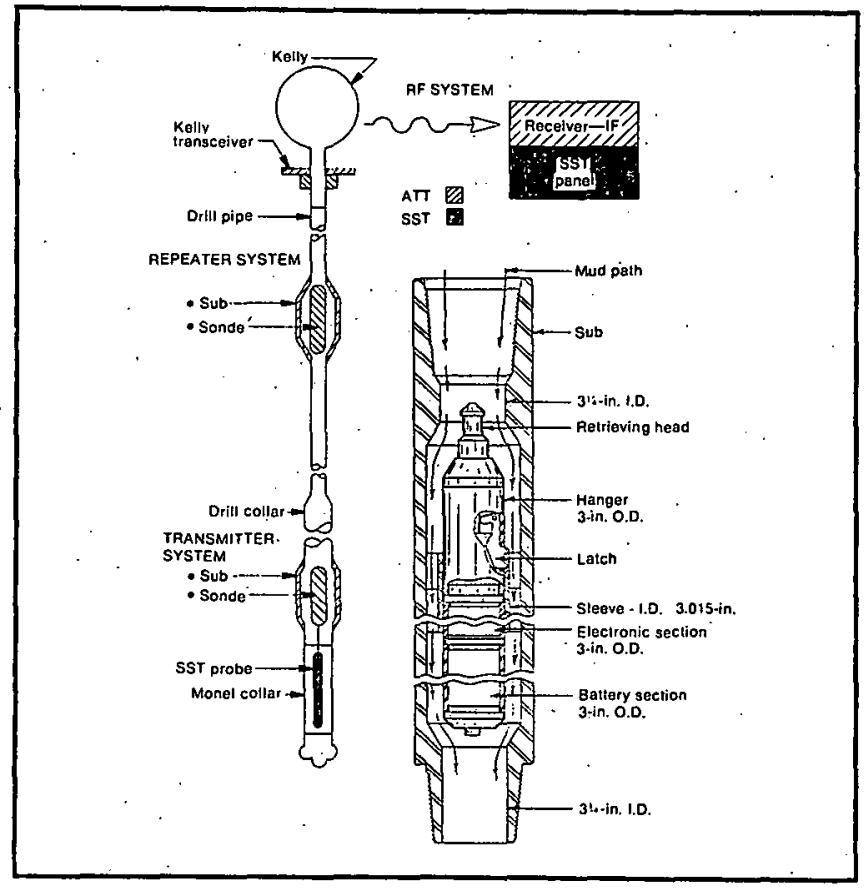

Figure 29. Sperry-Sun's Acoustic Telemetry System 


\section{DRILLING RIGS}

Rotary drilling rigs are designed for various depth ranges and can be either portable (mounted on trucks) or skid mounted. In either case, the overall drilling rig assembly including draw works, mud handling unit, and rotary table are modularized and assembled to meet specific drilling requirements. Mobile drilling rigs are preferable for drilling wells down to the 8-10,000 ft. range, however, the terrain may dictate that skid mounted units be used. Two main factors that affect rig choice are terrain and customer preference.

One drilling rig vendor (20) markets mobile units according to the following nominal depth ratings:

$$
\begin{array}{r}
\text {. } \quad 5,000 \mathrm{ft} \\
\text {. } \quad 6,500 \mathrm{ft} \\
\text {. } \quad 12,500 \mathrm{ft}
\end{array}
$$

Their skid mounted drilling units are rated according to the following nominal depths:

- 6,000 to $10,000 \mathrm{ft}$

- 8,000 to $13,000 \mathrm{ft}$

- 10,000 to $17,000 \mathrm{ft}$

- 14,000 to $21,000 \mathrm{ft}$

- 15,000 to deepest.

Offshore drilling skid units are essentially the same as inland drilling skid units. 
In recent years, new drilling rigs based on flexible drillstems have been developed and are currently being tested. Figure 30 shows a prototype rig developed by Roy H. Cullen Research (21). Major features of this drilling technique include:

- Flexible drill stem with high tensile, burst, and crush. strengths.

- Retractor consisting of an endless chain of hydraulic clamps

- Powerful downhole electric motor-speed variable from surface

Continuous circulation of drilling fluids even while tripping the flex-stem 


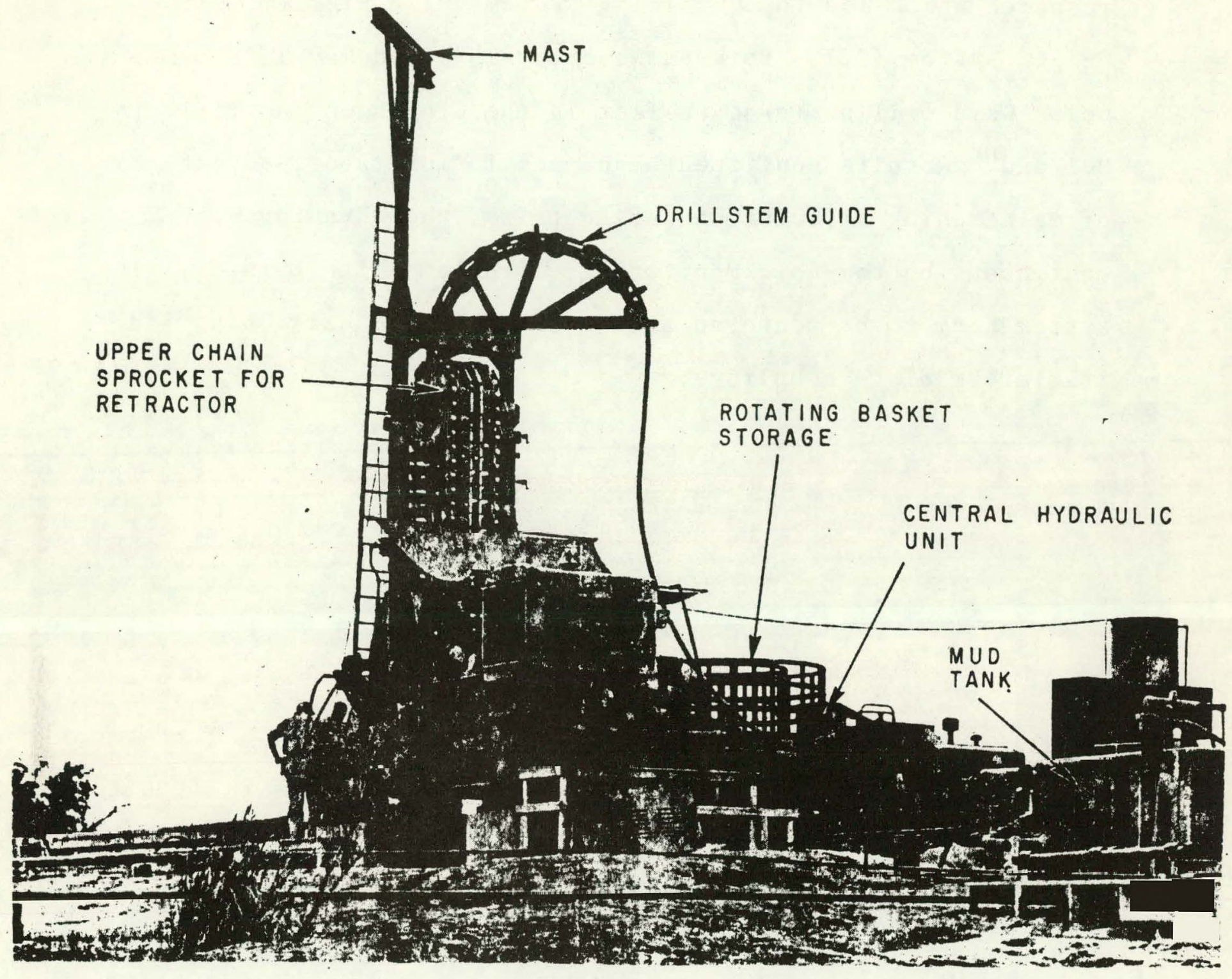

Figure 30. Rear View of Rig Shows the Surface Components, Including Mast, Flex-Stem, Rotating Basket for Storing Flex-Stem

This experimental rig was designed to accommodate 2-5/8" O.D. flex-stem. 
In 1960, Institute Francais du Petrole (IFP) initiated research which led to a drilling system quite similar to the Cullen system (22). Between November 1974 and May 1975, nine holes were drilled to 4,500 feet in the Groningen gas field in Holland. Results confirmed high penetration rates, advantages of maintaining circulation during trips, and advantages of continuous bottom-hole monitoring.' Problems with this drilling system seem to be centered around the flexible drill pipe and its intermediate couplings. 
DISTRIBUTION :

Tom Anderson

Venture Innovations

P.0. Box 35845

Houston, TX 77035

Ed Bingman

Shell 0 il Company

P.O. Box 2099

Houston, TX 77001

Larry Diamond

Dyna-Drill

P.0. Box C-19576

Irvine, CA 92713

John E. Fontenot

NL Petroleum Services

P.O. Box 60087

Houston, TX 77205

Dr. Melvin Friedman

Center for Tectonophysics and Dept. of Geology

Texas A\&M University

College Station, TX 77843

Tom Turner

Phillips Petroleum Company

Geothermal Operations

655 East 4500 South

Salt Lake City, UT 87107

Jim Kingsolver

Smith Tool

P.0. Box C-19511

Irvine, CA 92713

Tom Warren

Amoco Production Company

P.O. Box 591

Tu1sa, OK 74102
James W. Langford

Security Division

P.0. Box 24647

Dallas, TX 75224

Harvey E. Mallory

P.0. Box 54696

Tulsa, OK 74155

Gene Po1k

NL Baroid

6400 Uptown B1vd., $365 \mathrm{~W}$

A1buquerque, NM 87110

Del E. Pyle

Union Geothermal Division

Union Oil Co. of Callfornia

Union Oil Center

Los Angeles, CA 90017

John C. Rowley

Los Alamos National Labs

Mail Stop 570

Los Alamos, NM 8754.5

William D. Rumbaugh

otis

Research \& Development

P.O. Box 34380

Dallas, TX 75234

Dwight Smith

Halliburton

Drawer 1431

Duncan, OK 73533

Ed Martin

Superior Oil

Eastern Division

P.0. Box 51108 OCS

Lafayette, IA 70505 
DISTRIBUTION cont.

Jan Mares, Ass.'t. Secretary

for Fossil Energy

U.S. Department of Energy

Washington, DC 20585

Harold Shoemaker. (3)

Morgantown Energy Technology Center

P.O. Box 880

Morgantown, WV 26505

Ray Williams (3)

Bartlesville Energy Technology

Center

P.0. Box 1398

Bartlesville, OK 74003

A. L. McFali (3)

NL Petroleum Services

P.0. Box 60087

Houstion, TX 77205

U.S. Department of Energy

Geothermal \& Hydropower Division

Forresta1 B1dg., CE 324

1000 Independence Ave. S.W.

Washington, D.C. 20585

Attn: J. Bresee

D. Clements

R. Toms.

D. A11en

4700 E. H. Beckner

4730 W. D. Weart

4740 R. K. Traeger

4741 J. R. Kelsey

4743 H. C. Hardee

4746 B. Granoff

4747 P. J. Hommert

4748 B. E. Bader

4750 V. L. Dugan

4752 H. M. Dodd

4753 D. A. Northrop

4755 B. W. Marsha11

4756 D. Engi

8214 M. A. Pound

3141 L. J. Erickson

31.51 W. L. Garrier 


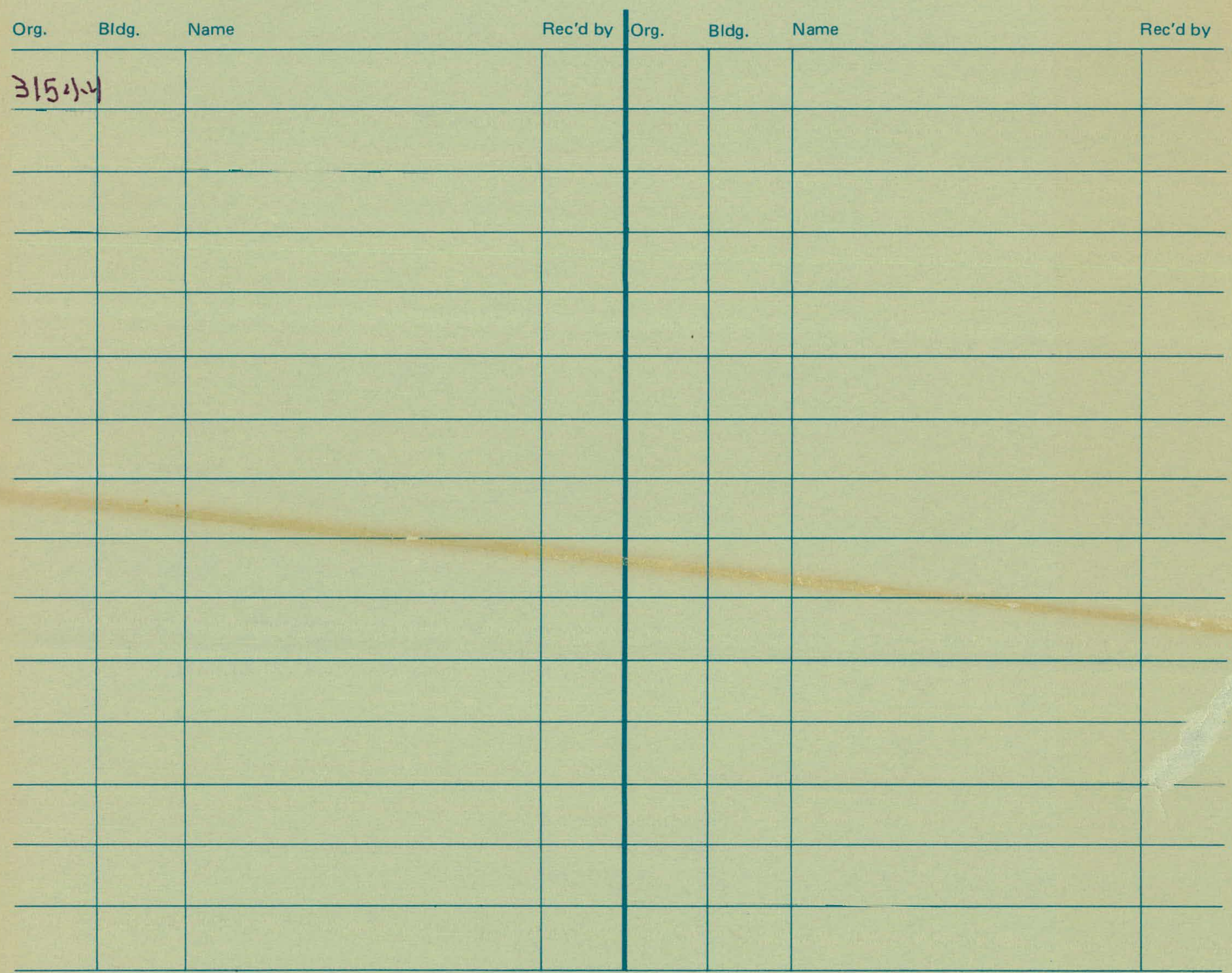

